\title{
Dust Identification over Arid and Semiarid Regions of Asia Using AIRS Thermal Infrared Channels
}

\author{
Hui Xu, Tianhai Cheng, Donghai Xie, Jiaguo Li, Yu Wu, and Hao Chen \\ Institute of Remote Sensing and Digital Earth, Chinese Academy of Sciences, Haidian District, Beijing 100101, China \\ Correspondence should be addressed to Tianhai Cheng; cthy@irsa.ac.cn
}

Received 5 June 2014; Revised 10 August 2014; Accepted 12 August 2014; Published 31 August 2014

Academic Editor: Hesham El-Askary

Copyright ( 2014 Hui Xu et al. This is an open access article distributed under the Creative Commons Attribution License, which permits unrestricted use, distribution, and reproduction in any medium, provided the original work is properly cited.

\begin{abstract}
Asia dust generated in northern China exerts significant influences on regional air quality, weather, and climate. In this study, a dust identification algorithm over arid and semiarid regions of Asia was proposed based on the thermal observations of atmospheric infrared sounder (AIRS). Firstly, a combination of the line-by-line (LBL) and discrete ordinates radiative transfer (DISORT) model was utilized to investigate the thermal infrared signatures of dust and cloud in $800-1250 \mathrm{~cm}^{-1}$ region. Secondly, six channels in the thermal infrared region were selected from AIRS to monitor dust from space, and a further sensitivity analysis for dust and cloud under different conditions was also performed. Then, the description of the detailed identification method was provided based on distinct thermal infrared signature of dust. At last, several dust events that observed in northern China between the period of 2008 and 2012 were analyzed, and the usefulness of monitoring the outbreaks of Asian dust was emphasized through the comparison with moderate resolution imaging spectroradiometer (MODIS) visible observations and cloud aerosol lidar with orthogonal polarization (CALIOP) data in this study.
\end{abstract}

\section{Introduction}

In spring, the arid and semiarid regions of northern China are dry and often windy [1], providing the favorable conditions for the development of dust activities [2,3] and making China the most important dust source regions in Eastern Asia [46 . The elevated mineral dust which is mainly distributed in the troposphere [7-10] can affect climate on various spatial and temporal scales [11] through a series of complex direct and indirect radiative forcing [12-15]. Recently, owing to the climate change and excessive land use, dust events occur more frequently around the world $[16,17]$. Therefore, it is necessary to monitor its distribution and study how it changes.

Since the advent of satellite technology, monitoring dust from space has become one of the most important focuses among the many atmospheric scientific issues [18]. In last decade, much progress has been made in the remote sensing of dust using various VIR (visible and near-infrared) and TIR (thermal infrared) techniques [19-27]. Recently, the potential possibility of utilizing the microwave and Lidar measurements to monitor dust from space was also discussed by many researchers [28-30]. Among the many techniques, it has been proved that the infrared hyperspectral resolution remote sensing has the distinct advantage in monitoring dust over arid and semiarid surfaces and even in the nighttime [31-37]. Sokolik [31] carried out the research on the infrared hyperspectral radiative signature of wind-blown mineral dust, concluding that dust has a significant influence on the retrieval accuracy of surface and atmospheric parameters. Hong et al. [32] made a deep investigation on the infrared signature of overlapping cirrus clouds and mineral dust, which founds that the the thermal infrared spectral features in the $1100-1200 \mathrm{~cm}^{-1}$ and $1400-1850 \mathrm{~cm}^{-1}$ regions can be used to retrieval the optical thicknesses of the dust and cirrus cloud, respectively. Pierangelo et al. [26, 33, 34] proposed an algorithm to retrieve the optical depth, effective radius, and height of dust over the Atlantic Ocean from AIRS data based on the fast line-by-line Automatized Atmospheric Absorption Atlas (4A) model. DeSouza-Machado et al. [35, 36] using AIRS observations developed fast optical depth and height retrieval methods through the analysis of infrared dust spectral signatures over ocean, and the results show good 
correlation with MODIS products. Based on the RTTOV IDVAR algorithm, Yao et al. [37] retrieved the Asia dust top height and infrared optical depth over land from AIRS observations, and the optical depths retrieved from AIRS correlate favorably with the visible optical depths from OMI.

Although remote sensing dust using hyperspectral infrared measurement has made considerable progress in the last decade, more efforts still need to do both in the forward simulation and retrieval method, especially at nighttime and even when the condition of dust and cloud are cooccurrence in the same atmospheric column. As the accurate dust detection result is critically important for the properties retrieval, this study focuses on the dust identification over arid and semiarid regions using thermal infrared hyperspectral sounding data from AIRS. The paper is organized as follows: a description of used satellite remote sensing dataset is given in Section 2; Section 3 makes a comprehensive analysis on the thermal infrared signatures of dust and cloud, and the detailed dust identification algorithm is also given in this section; detection results and comparison with MODIS and CALIOP observations are performed in Section 4; summary and conclusions are given in the closing section.

\section{Satellite Remote Sensing Data}

2.1. AIRS. The AIRS instrument [38] on board Earth Observing System (EOS) Aqua platform in the A-Train constellation which launched on May 4, 2002, is the first new generation of high spectral resolution of infrared sounder. It has 2378 infrared channels which can measure the earth outgoing radiation in 3.7-15.4 $\mu \mathrm{m}$ region $(3.75-4.58,6.2-$ 8.2 , and $8.8-15.4 \mu \mathrm{m})$ with a spectral resolution of $\lambda / \Delta \lambda=$ 1200 and spatial resolution of $13.5 \mathrm{~km}$ (nadir field of view). The primarily task of AIRS is to obtain the highly accurate temperature profiles within the atmosphere plus a variety of additional Earth/atmosphere products (surface temperature, water vapor, and cloud properties) [39-41] to conduct the further research on climate changes and weather forecasting. Additionally, AIRS can also measure the information of dust properties by taking advantage of the high spectral resolution longwave dust-sensitive radiance measurements as described above. In this study, the daily level $1 \mathrm{~B}$ datasets which are downloaded from Goddard Earth Sciences Data and Information Services Center (GES DISC) are used to monitor and analyse the dust of Asia.

2.2. MODIS. The MODIS sensor shares the Aqua satellite with AIRS (there are no temporal artefacts on the observed scene between the two instruments) which has 36 channels with wavelengths from 0.41 to $14.385 \mu \mathrm{m}$ and nadir spatial resolutions of $0.25 \mathrm{~km}, 0.5 \mathrm{~km}$, and $1 \mathrm{~km}$ [42]. It is considered as a key instrument to improve our understanding of global dynamics and processes occurring on the land, in the oceans, and in the lower atmosphere. Its level 2 aerosol products [43] use three different algorithms (Ocean, Dark Target, and Deep Blue) to monitor the ambient aerosol optical thickness over the oceans globally and over the continents. The Deep Blue algorithm [20] was developed to get the aerosol optical depth over bright land areas. Generally speaking, high values of the deep blue optical depth over the arid and semiarid regions are usually related to more dust loading in the atmosphere, vice versa. Here, the level $1 B$ RGB composition images (R: channel 1, G: channel 4, and B: channel 3) and level 2 deep blue aerosol optical depth product (MYD04) which are downloaded from International Cancer Alliance for Research and Education (ICARE) is used to evaluate and analyse the results of proposed dust identification algorithm.

2.3. CALIOP. The Cloud Aerosol Lidar with Orthogonal Polarization (CALIOP) instrument on board the CALIPSO platform which can provide the unique measurements of the global vertical distributions of clouds and aerosols both at day and night [36]. It is a two-wavelength Lidar that transmits and receives backscattered light at laser wavelengths of $532 \mathrm{~nm}$ and $1064 \mathrm{~nm}$. The vertical resolutions are $30 \mathrm{~m}$ from the surface to $8 \mathrm{~km}$ altitude and $60 \mathrm{~m}$ above the $8 \mathrm{~km}$ altitude. The minimum horizontal resolution of a single profile is $330 \mathrm{~m}$, and a typical horizontal averaging interval is $5 \mathrm{~km}$ for aerosol and dust. CALIOP is a nadir only sensor which follows a similar ground track to AIRS (offset by $170 \mathrm{~km}$ from AIRS nadir). It is also a member of the A-Train constellation, which means that measurements from AIRS and CALIOP can be easily compared to each other. In this paper, the L1 $532 \mathrm{~nm}$ backscatter data and L2 aerosol subtype products from the CALIPSO Search and Subsetting web application are used to evaluate the dust identification results during nighttime.

\section{Physical Basis and Method}

3.1. Physical Basis. Generally, almost all dust events, especially the dust storms, are related to cold front and cyclone activities [1]; consequently, dust and cloud more often coexist in the same scene. In order to differentiate dust from other targets, the thermal infrared signatures of dust and cloud are investigated. To acquire the spectral brightness temperatures at the top of atmosphere, the discrete ordinates radiative transfer (DISORT) model in conjunction with a line by line (LBL) model is used to simulate the thermal infrared signatures of dust and cloud in the $800-1250 \mathrm{~cm}^{-1}$ region with a spectral resolution of $0.1 \mathrm{~cm}^{-1}$.

Considering that the optical properties of dust are mainly depending on the mineralogical composition and particle radius (the nonspherical effect is small over IR spectral range [44]), accurate refractive indices and size distribution are required for the simulation. Han et al. [45] founded that the Volz dust-like refractive indices [46] can well represent the optical properties of Asia dust. Therefore, the bulk extinction coefficient, single scattering albedo, and phase function of Asia dust are calculated with Lorentz-Mie scattering based on the dust-like refractive indices and OPAC typical accumulated dust size distribution [47]. For the description of cloud, the water and ice cloud is investigated. The optical properties of water cloud are calculated through LorentzMie scattering with an effective radius of $10 \mu \mathrm{m}$ [48], and the optical properties of ice cloud are derived from Baum et al. $[49,50]$ with an effective radius of $30 \mu \mathrm{m}$. 
Many researches have proved that dust is generally located around the $1-5 \mathrm{~km}$ in altitude [22, 26, 34, 37], and sometimes it can be transported to the $8-10 \mathrm{~km}$ [51] levels of atmosphere when the conditions permit. In present simulation, the spectral brightness temperatures of dust for a $3 \mathrm{~km}$ height in conjunction with an optical thickness of 1.0 (at infrared wavelength of $10 \mu \mathrm{m}, 1000 \mathrm{~cm}^{-1}$ in wavenumber) are simulated. In addition, the thermal infrared signatures of typical water and ice cloud [48] are also studied for the purpose of comparing and analyzing the spectrum difference between dust and cloud. The water cloud layer with an optical depth of 15.0 in an altitude of $1 \mathrm{~km}$ height was assumed, and the ice cloud layer is considered at a $10 \mathrm{~km}$ height atmosphere with an optical depth of 3.0. Moreover, the atmospheric molecular absorption is calculated from the LBL model based on the middle latitude winter standard atmospheric profile, the surface temperature, and emissivity are assumed as $290 \mathrm{~K}$ and 1.0, respectively. At last, the nadir infrared spectral brightness temperatures of clear sky, dust, and cloud are calculated through the DISORT and LBL models. Figure 1 shows the forward simulation results, and all the input variables are listed in Table 1.

From Figure 1(a), it is easy to see that the spectral segment of clear sky in $800-1250 \mathrm{~cm}^{-1}$ region is essentially flat except for the ozone strong absorption region (nearly around the region of $\left.1000-1060 \mathrm{~cm}^{-1}\right)$. However, in the present dust (Figure 1(b)), it not only decreases the brightness temperatures in the whole spectral region of $800-1250 \mathrm{~cm}^{-1}$ but also displays a "V" spectral shape which is resulted from a negative spectral slope in $800-1000 \mathrm{~cm}^{-1}$ subregion and a positive spectral slope in $1060-1250 \mathrm{~cm}^{-1}$ subregion. In addition, the overall variation patterns of the two subregions are nearly symmetric although the slope in the positive region is a little bit sharper. Unlike the spectral variation caused by dust, clouds reveal some different characteristics. In Figure 1(c), it is obvious to see that ice cloud generally shows a reversed spectral feature with dust. The spectrum in $800-1000 \mathrm{~cm}^{-1}$ region is marked with a positive slope whereas the variation of brightness temperatures in $1060-1250 \mathrm{~cm}^{-1}$ region is generally flat. For the spectral signature of water cloud, it is much more similar to the clear sky, even though the brightness temperatures in the subregion of $800-1000 \mathrm{~cm}^{-1}$ are generally higher than the subregion of 1060-1250 $\mathrm{cm}^{-1}$ (Figure 1(d)).

Actually, the obvious "V" spectral shape of dust in the region of $800-1250 \mathrm{~cm}^{-1}$ probably provides us an opportunity to monitor it from space.

3.2. Channel Selection. It is common to know that water vapor and ozone are the main absorption gases in the thermal infrared region of $800-1250 \mathrm{~cm}^{-1}$. Thus, the selected dust observation channels should be either highly sensitive to dust or less/no sensitive to water vapor and ozone. Actually, there are many channels that may satisfy the criteria. However, as the extinction abilities of dust in the adjacent channels are basically similar, consequently, the brightness temperature differences between these channels are generally small, and then the spectral shape of dust can be easily affected by
TABLE 1: The input parameters of dust and cloud for the brightness temperature simulation.

\begin{tabular}{lccc}
\hline & Dust & Ice cloud & Water cloud \\
\hline Optical depth & 1.0 & 3.0 & 15.0 \\
Layer height & $3 \mathrm{~km}$ & $10 \mathrm{~km}$ & $1 \mathrm{~km}$ \\
$\begin{array}{l}\text { Particle effective } \\
\text { radius }\end{array}$ & $1.3 \mu \mathrm{m}$ & $30 \mu \mathrm{m}$ & $10 \mu \mathrm{m}$ \\
\hline $\begin{array}{l}\text { Surface temperature } \\
\text { Surface emissivity }\end{array}$ & $290 \mathrm{~K}$ \\
Atmosphere profile & Middle latitude winter atmospheric profile \\
\hline
\end{tabular}

TABLE 2: The selected AIRS dust observation channels.

\begin{tabular}{lccc}
\hline $\begin{array}{l}\text { Chanel } \\
(\mathrm{id})\end{array}$ & $\begin{array}{c}\text { Wavenumber } \\
\left(\mathrm{cm}^{-1}\right)\end{array}$ & $\begin{array}{c}\text { Wavelength } \\
(\mu \mathrm{m})\end{array}$ & Transmittance \\
\hline 504 & 811.78 & 12.32 & 0.90 \\
761 & 901.00 & 11.09 & 0.95 \\
953 & 980.36 & 10.20 & 0.93 \\
1179 & 1092.92 & 9.15 & 0.90 \\
1237 & 1123.13 & 8.90 & 0.92 \\
1307 & 1239.68 & 8.06 & 0.67 \\
\hline
\end{tabular}

nondust factors. Therefore, in order to more accurately depict the unique "V" spectral shape of dust in the $800-1250 \mathrm{~cm}^{-1}$ region, six channels with obviously different dust extinction abilities are selected, as shown in Table 2. And the redundant channels with similar transmittance to these six channels are removed, even though they also can be used to monitor dust from space.

It is interesting to note that all the selected channels have a high transmittance except for the $1239.68 \mathrm{~cm}^{-1}$ channel. Under the condition of clear sky, the radiances measured in this channel will generally low than the others. However, as it has less dust extinction compared with other channels, the relative changes in radiances observed in this channel can be used as a good indicator of dust.

3.3. Sensitivity Analysis. Based on the selected AIRS observation channels, the spectrum variation patterns of dust and cloud under different conditions are further discussed. The high resolution monochromatic radiances of the scenes are integrated with the filter function over the bandwidth of selected channels to acquire the channel brightness temperatures. Specially, if not specified, the default input parameters of the following simulation are set as values listed in Table 1, and one parameter changes, and the others keep constant.

3.3.1. Dust. Figure 2 shows the dependence of the channel spectral brightness temperatures on the optical depth, layer height, and effective radius of dust. In addition to the " $\mathrm{V}$ " spectral shape of dust that is discussed in Section 3.1, other interesting features can be also noticed from Figure 2. 


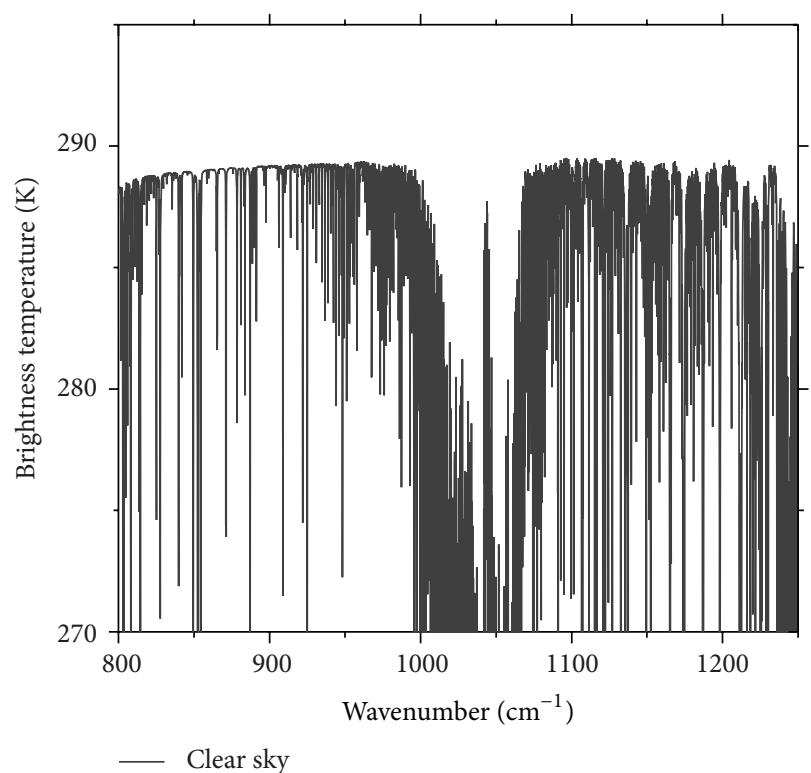

(a)

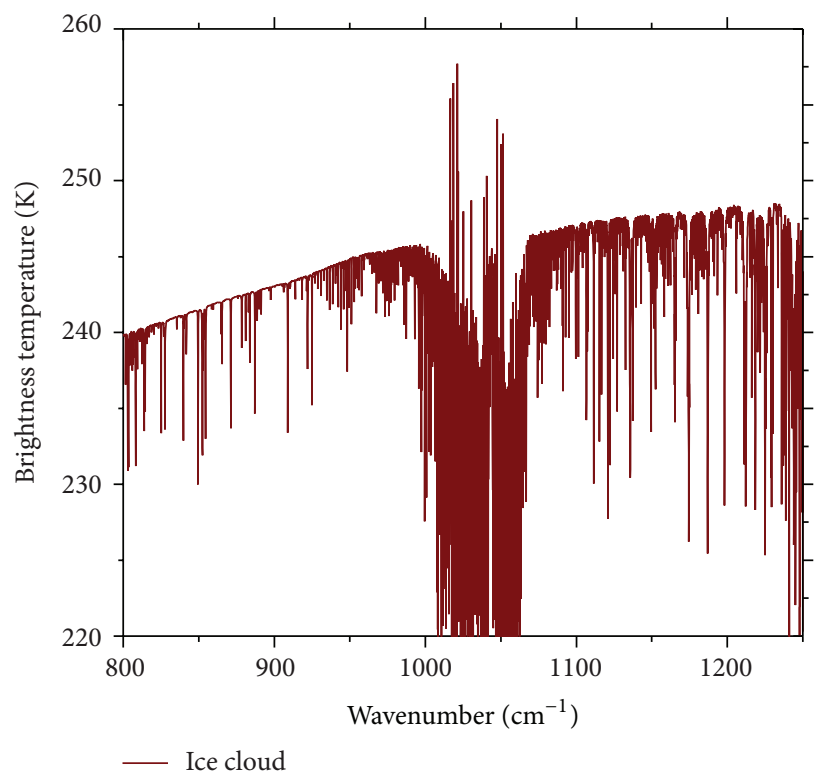

(c)

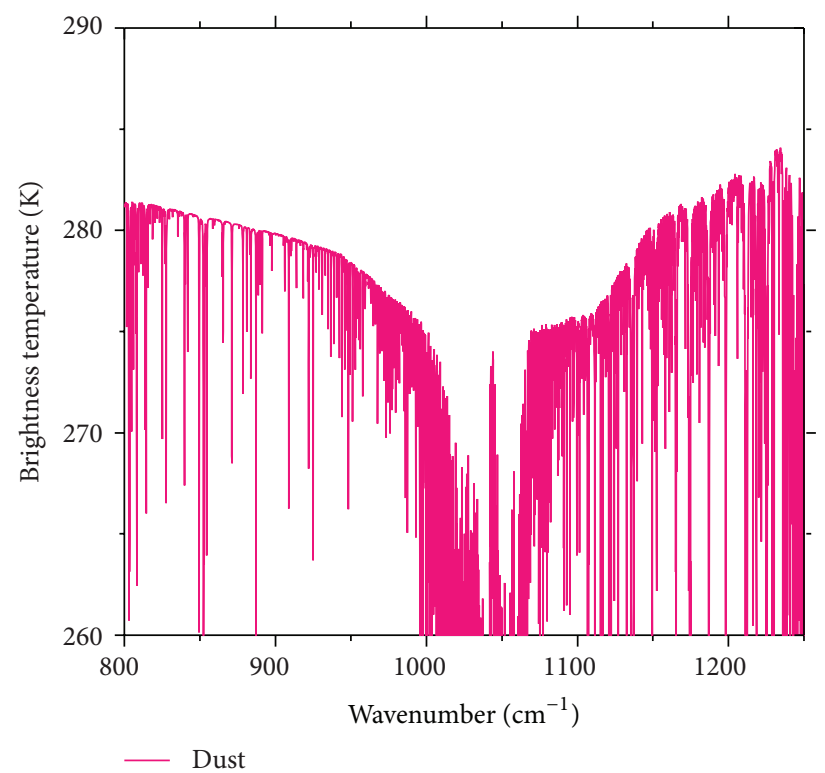

(b)

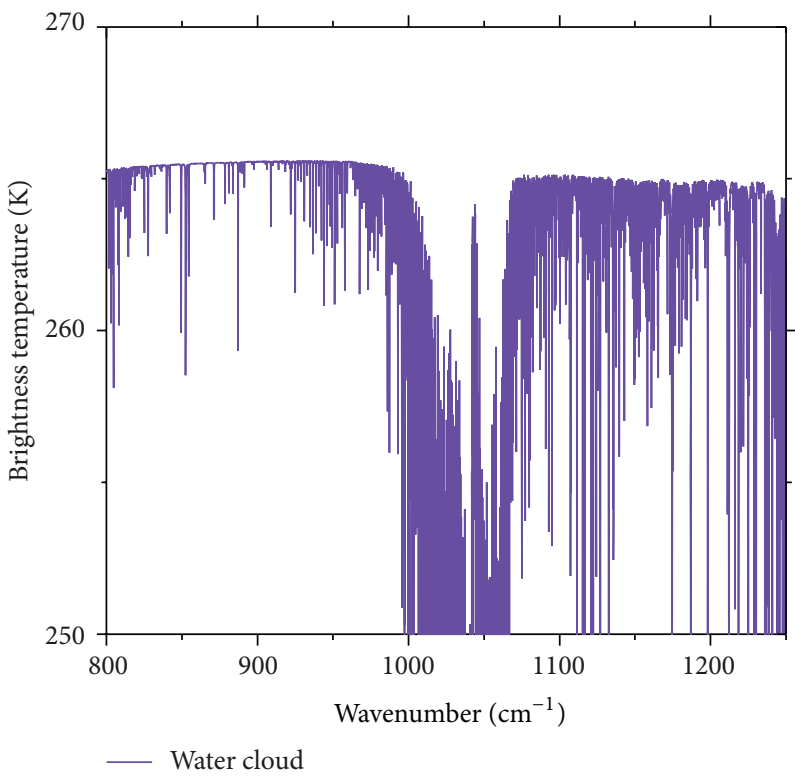

(d)

FIGURE 1: The simulated nadir-viewed spectral brightness temperatures of (a) clear sky, (b) dust, (c) ice cloud, and (d) water cloud.

Figures 2(a) to 2(d) show the spectral variation of dust with optical depth. It is easy to see that the "V" spectral shape is not particularly obvious when dust has a low optical depth. However, with the increase of the optical depth, the slopes of the spectrum in both the $800-1000 \mathrm{~cm}^{-1}$ and $1060-1200 \mathrm{~cm}^{-1}$ regions become more and more sharp, and this variation characteristic is also applicable to the changes of dust layer height. As shown in Figure 2(e), with the increase of dust layer altitude, the "V" spectral shape becomes more and more clear. These indicate that the thermal infrared measurements are especially suitable for the detection of dust with high optical depth and altitude; however, dust layer close to the surface with a low optical depth can be hardly identified. Figure 2(f) shows the variation of channel brightness temperatures with the change of dust effective radius. In Figure 2(f), another interesting point to be noted is that the spectral brightness temperature differences between channels become smaller with the increase of particle effective radius. That is to say, the coarse particles can weaken the particular "V" spectral shape of dust.

3.3.2. Cloud. For the detailed spectrum analysis of cloud in the selected channels, not only ice and water clouds are discussed (Figures 3 and 4 ) but also the mixed-phase cloud is 


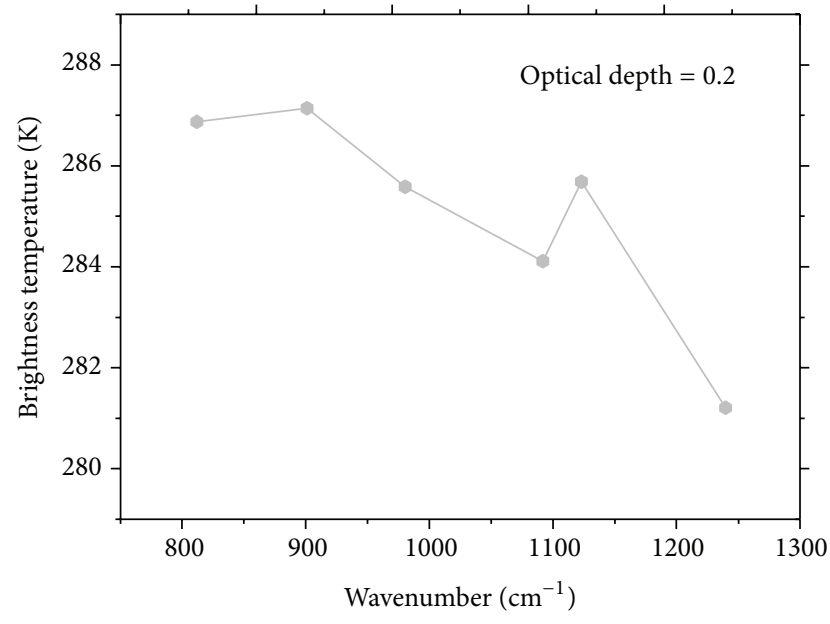

(a)

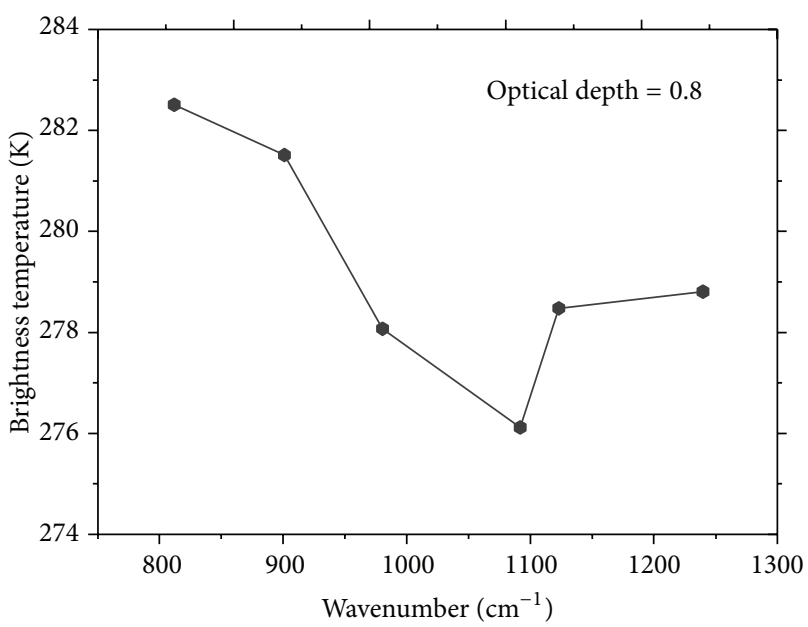

(c)

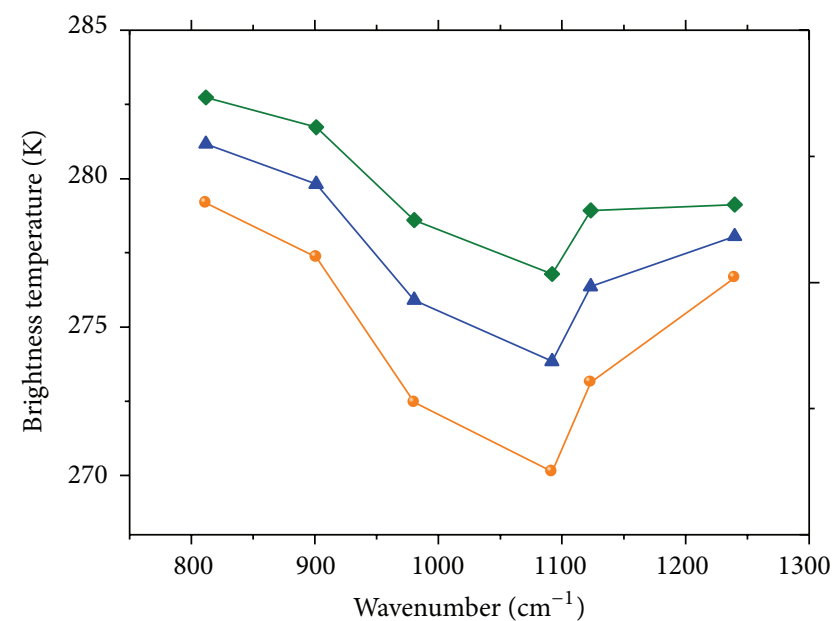

- Height $=1 \mathrm{~km}$

Height $=3 \mathrm{~km}$

$\multimap$ Height $=5 \mathrm{~km}$

(e)

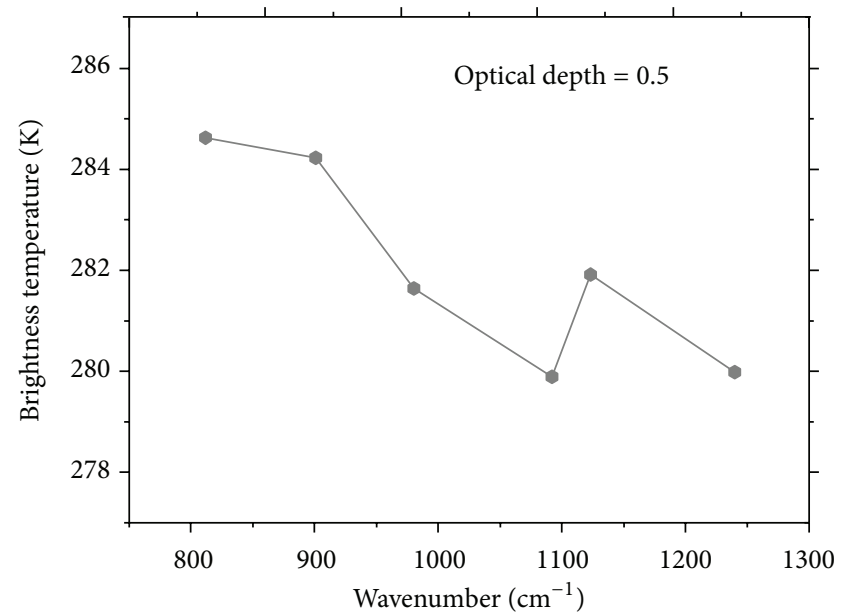

(b)

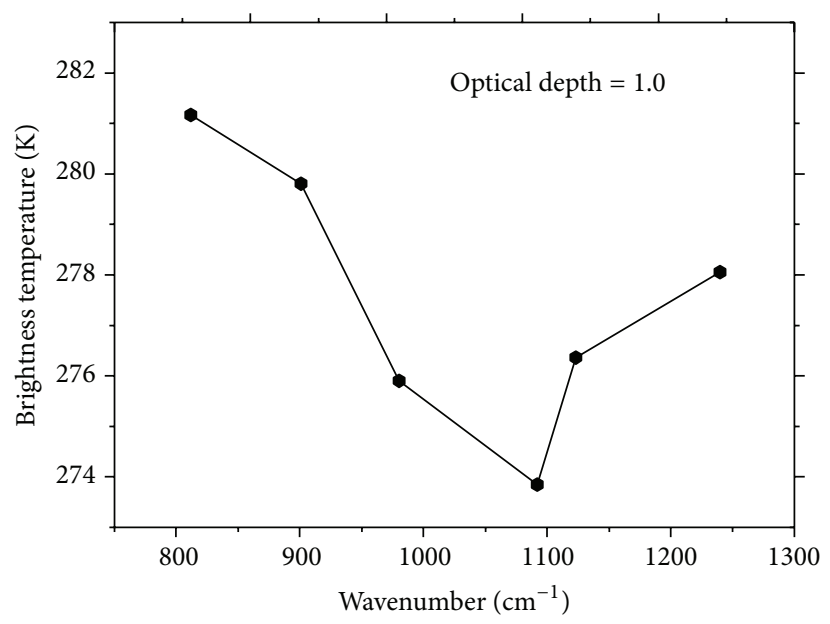

(d)

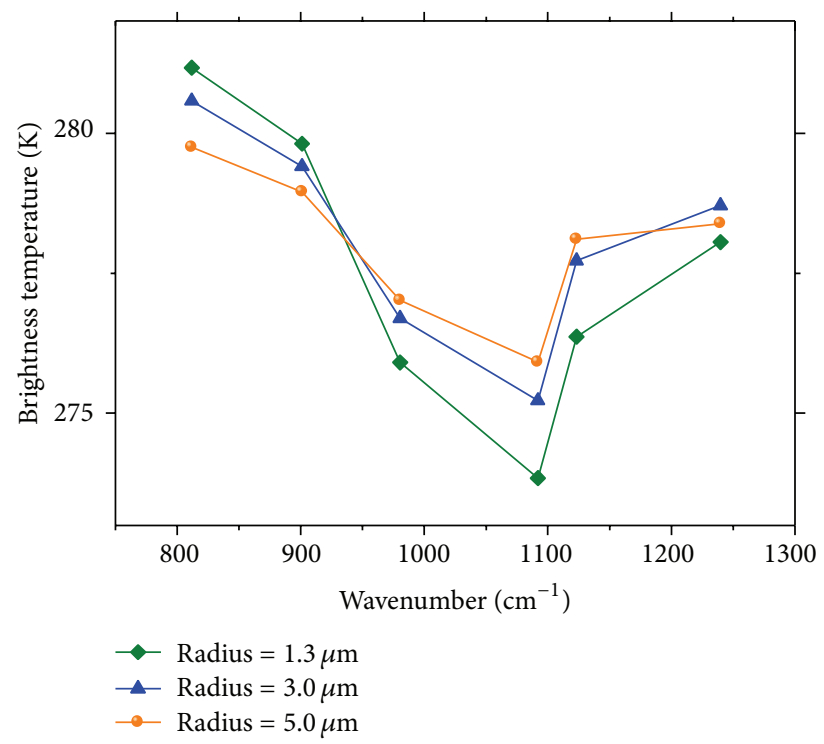

(f)

FIgURE 2: The effects of (a-d) optical depth, (e) layer height, and (f) effective radius on the spectrum of dust. 
investigated (Figure 5), as the mixed-phase clouds are more frequent in the cold front coexist with dust storms over the semiarid region.

Like the case for dust, the spectral signature of ice cloud becomes more pronounced as the optical depth (shown in Figures 3(a) to 3(d)) and layer height (shown in Figure 3(e)) increase, and the spectrum in $800-1000 \mathrm{~cm}^{-1}$ subregion is gradually featured with a positive slope. It is also interesting to see that the slopes of the spectrum in both the $800-1000 \mathrm{~cm}^{-1}$ and $1060-1250 \mathrm{~cm}^{-1}$ subregions are sensitive to the variation of ice particle effective radius (as shown in Figure 3(f)). Specially, ice particles with small effective radius (radius = $10 \mu \mathrm{m}$ in Figure 3(f)) will reveal a reversed spectral shape with dust, as evident from Figure 3(f) (positive slope in 800$1000 \mathrm{~cm}^{-1}$ subregion and negative slope in $1060-1250 \mathrm{~cm}^{-1}$ subregion).

The thermal infrared signature of water cloud is shown in Figure 4. In general, the spectral brightness temperatures in the $800-1000 \mathrm{~cm}^{-1}$ subregion gradually become higher than them in the $1060-1250 \mathrm{~cm}^{-1}$ subregion, with the increase of water cloud optical depth (shown from Figures 4(a) to 4(d)). Moreover, it is evident from Figure 4 that the slope of the spectrum in $1060-1250 \mathrm{~cm}^{-1}$ subregion is becoming nearly zero along with the increasing of water cloud optical depth and layer height. Similar to the dust and ice cloud cases, the increase of water droplet effective radius will decrease the brightness temperature differences in these selected channels, as shown in Figure 4(f).

For the case of mixed-phase cloud, the optical properties are calculated following the formulations developed by Liou [52], and $\mathrm{Ou}$ et al. [53] using the optical model developed a mixed-phase cloud retrieval method for the sensor of Visible Infrared Imaging Radiometer Suite (VIIRS):

$$
\begin{gathered}
\omega_{\text {mix }}=\frac{\tau_{s}}{\tau}=\frac{\omega_{i} \tau_{i}+\omega_{w} \tau_{w}}{\tau_{i}+\tau_{w}}, \\
l_{\text {mix }}=\frac{\omega_{i} \tau_{i} l_{i}+\omega_{w} \tau_{w} l_{w}}{\tau_{s}}, \\
f_{\text {mix }}=\frac{\omega_{i} \tau_{i} f_{i}+\omega_{w} \tau_{w} f_{w}}{\tau_{s}},
\end{gathered}
$$

where $\omega_{\text {mix }}, l_{\text {mix }}$, and $f_{\text {mix }}$ are the mixed-phase single scattering albedo, Legendre polynomial expansion coefficients, and phase function. Parameters $\tau_{s}$ and $\tau$ are the scattering optical depth and total optical depth of mixed-phase cloud, respectively, with subscripts $i$ and $w$ denoting ice and water clouds. Figures 5(a) and 5(b) show the spectral brightness temperatures of mixed-phase clouds with $1 \mathrm{~km}$ and $10 \mathrm{~km}$ in altitude, respectively.

From Figure 5, it is clear to see that the spectral variation of mixed-phase cloud is generally between the spectral shapes of ice $\left(\right.$ Ice $_{(\text {optical depth })}=10.0$, Water (optical depth $\left.)=0.0\right)$ and water cloud (Ice $_{\text {optical depth) }}=0.0$, Water optical depth) $\left.=10.0\right)$, and the spectral characteristic of mixed-phase cloud is basically determined by the fractions of ice and water cloud particles in it. Another interesting point that can be intuitively identified is that the thermal infrared signature of low level mixed-phase cloud is generally consistent with that of water cloud (shown in Figure 5(a)); however, if the mixed-phase cloud locates at a high level atmosphere, it would reveal a spectral signature more similar to the ice cloud (shown in Figure 5(b)).

3.3.3. Cloud over Dust. Many dust monitor researches have focused on the cases of cloud and dust layers which are not cooccurring in the same atmospheric column. However, they are frequently cooccurring over the northwest of China. To investigate the impact of cloud on spectral signature of dust, forward simulation experiments in the cases of thin (optical depth set as 1.0) and thick (optical depth set as 3.0) ice cloud overlapping low level dust are conducted, as shown in Figures 6(a) and 6(b), respectively.

In Figure 6(a), it is intuitive to see that the spectral brightness temperatures are depressed with increasing the optical depth of underlying dust. And the spectral shape is gradually transformed from ice cloud only to dust only. As shown in Figure 6(a), when the optical depth of the underlying dust is larger than that of the thin ice cloud, the spectral signatures of cloud-dust coexisting are highly consistent with that of dust only. However, if the dust layer is covered by a thick ice cloud, as shown in Figure 6(b), the spectral signatures of cloud-dust coexisting conditions are different from those for ice cloud only or dust alone, especially in the $800-1000 \mathrm{~cm}^{-1}$ subregion. This implies that the case of thick ice cloud overlapping low level dust cannot be easily detected by the thermal infrared measurements.

3.4. Method. In general, the spectral characteristics discussed in the preceding context imply that dust has a unique thermal infrared signature in the region of $800-1250 \mathrm{~cm}^{-1}$. Indeed, this distinct spectral shape provides us a reliable way to monitor dust through the thermal infrared measurements. Based on the analysis of channel spectral signature, several thresholds and combinations of selected ARIS channels were chosen to identify dust over arid and semiarid region, which are listed in Table 3. The entire dust test that is listed in Table 3 should generally provide an almost unique signature of dust in the thermal infrared. For any AIRS FOV, if test passes the threshold, it denotes that the pixel is contaminated by dust; otherwise, the FOV is flagged as not dust contaminated, finally.

\section{Results and Discussion}

4.1. Case: 30 March 2008. Taklamakan Desert is the world's largest shifting sand desert which is located in Central Asia (northwest China). Figure 7(a) shows a dust event on 30 March, 2008, sweeping across the northern Taklimakan Basin (red arrows in Figure 7(a)) which is surrounded by Kunlun Mountains in south and Tian Shan Mountains in north.

In order to evaluate the discussed Asia dust thermal infrared signature in the preceding context (Section 3), the brightness temperatures of the selected six channels in the dust region (the blue box region depicted in Figure $7(\mathrm{a})$ ) are extracted form AIRS observation, as shown in Figure 7(b). The distinct "V" shape of dust can be directly acquired from 


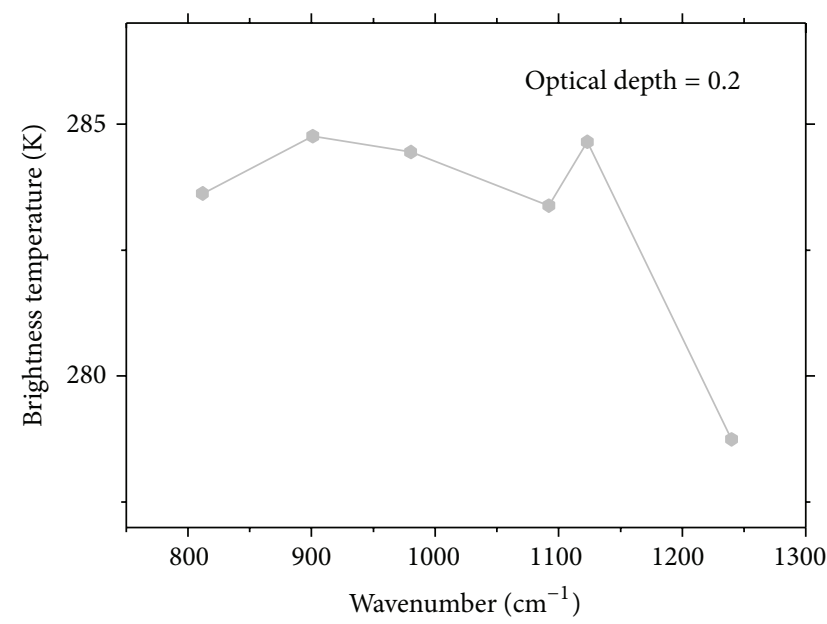

(a)

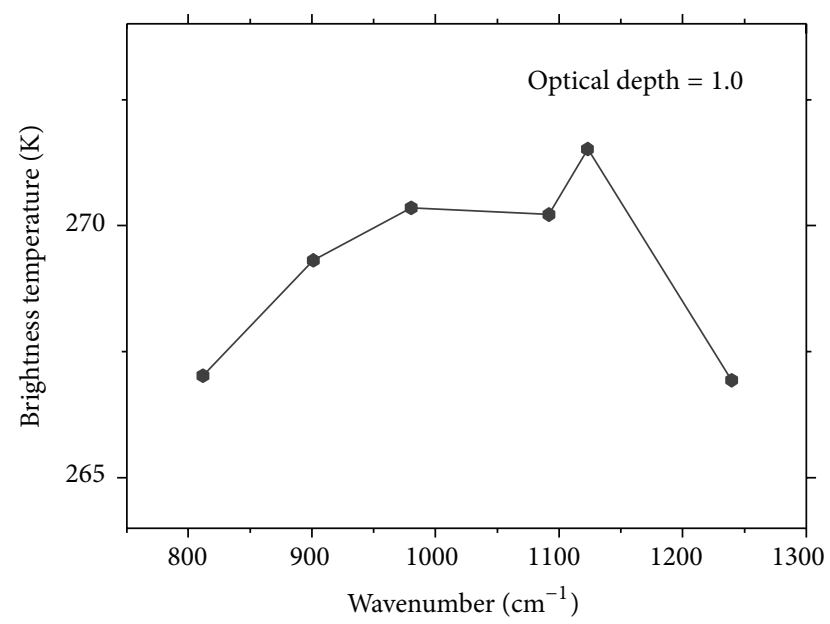

(c)

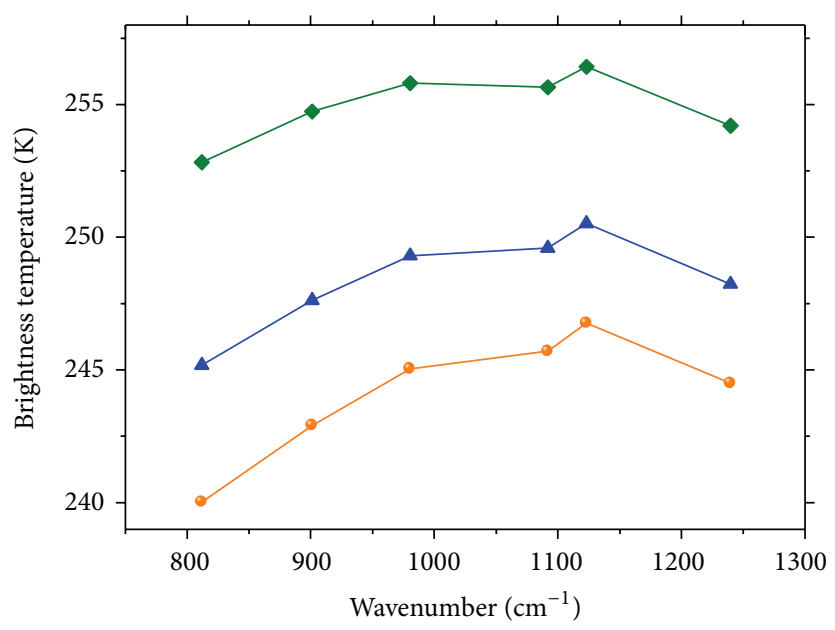

- Height $=6 \mathrm{~km}$

—— Height $=8 \mathrm{~km}$

$\rightarrow$ Height $=10 \mathrm{~km}$

(e)

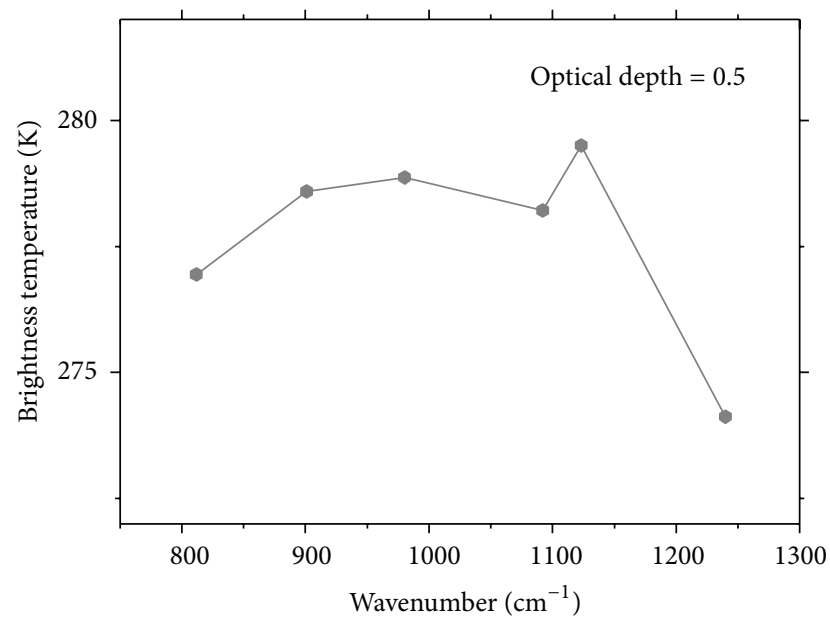

(b)

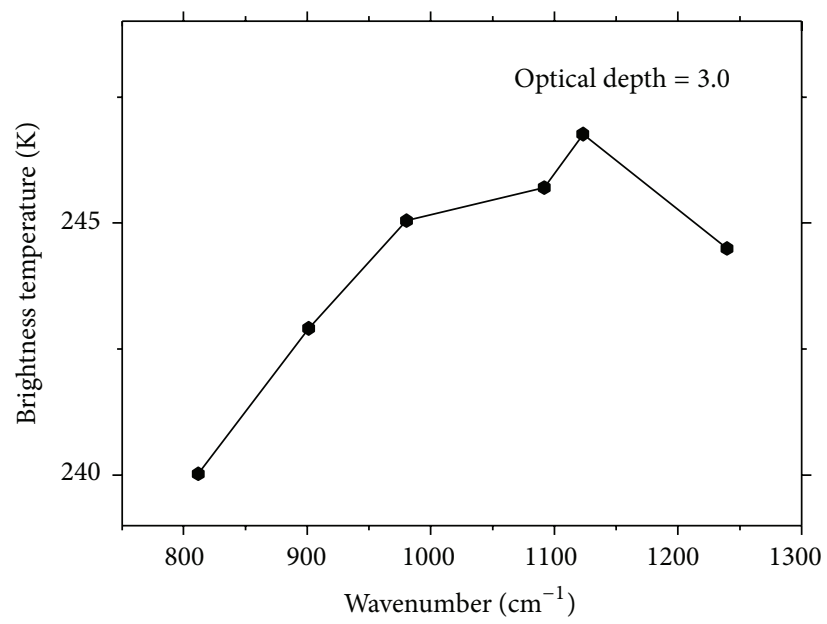

(d)

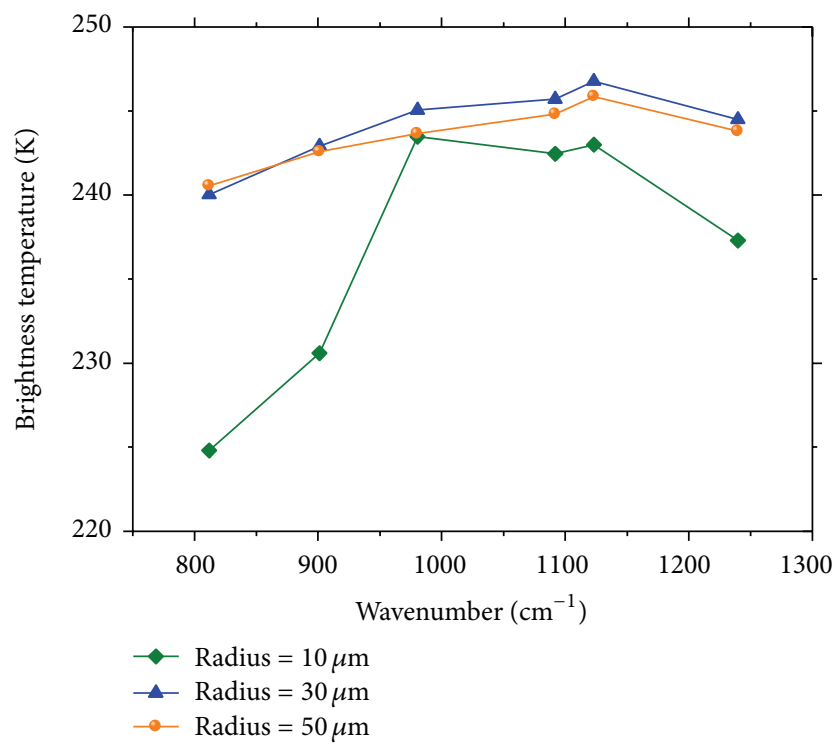

(f)

FIgURE 3: The effects of (a-d) optical depth, (e) layer height, and (f) effective radius on the spectrum of ice cloud. 


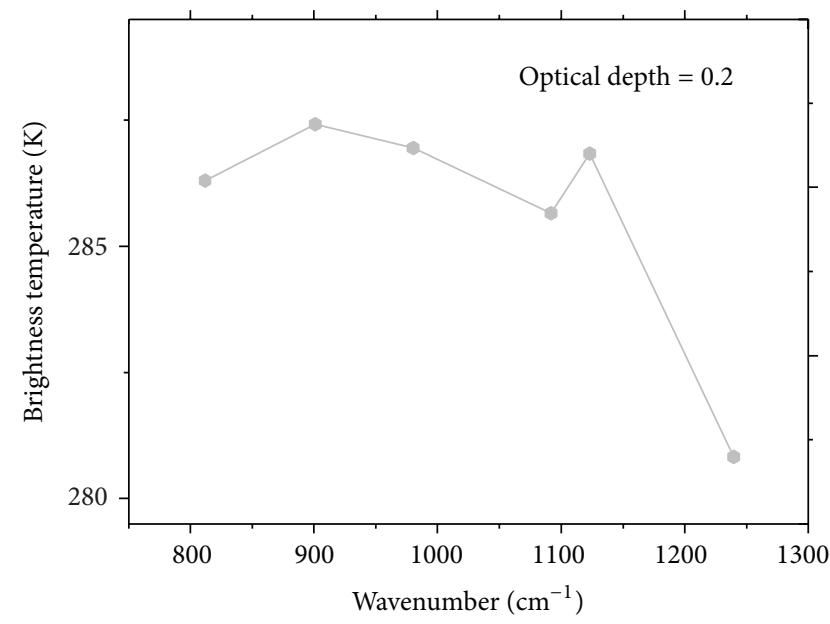

(a)

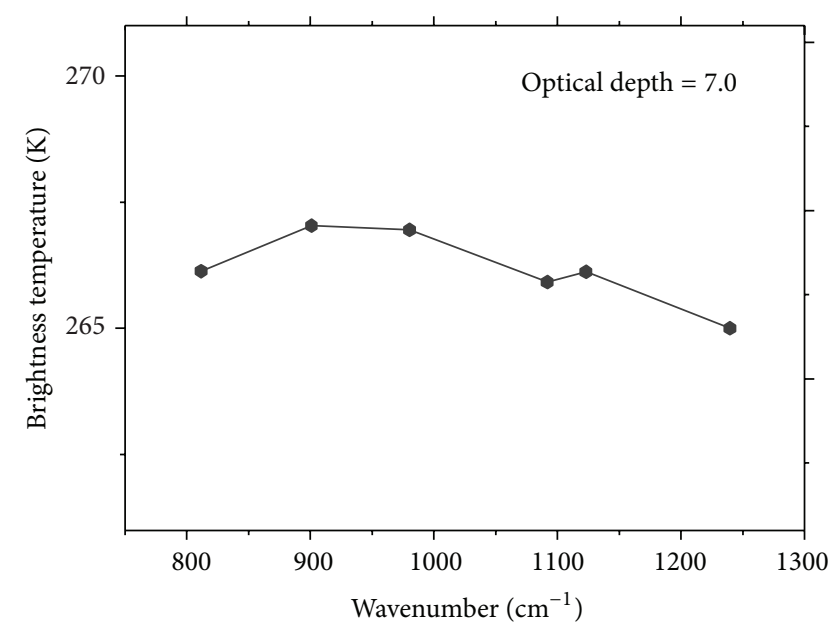

(c)

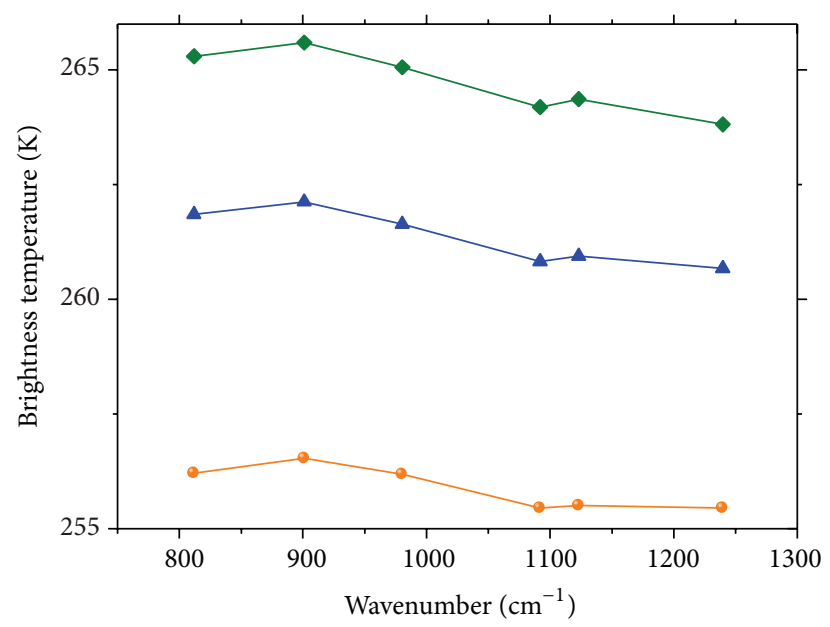

- Height $=1 \mathrm{~km}$

$\_$ـ Height $=2 \mathrm{~km}$

$\multimap$ Height $=3 \mathrm{~km}$

(e)

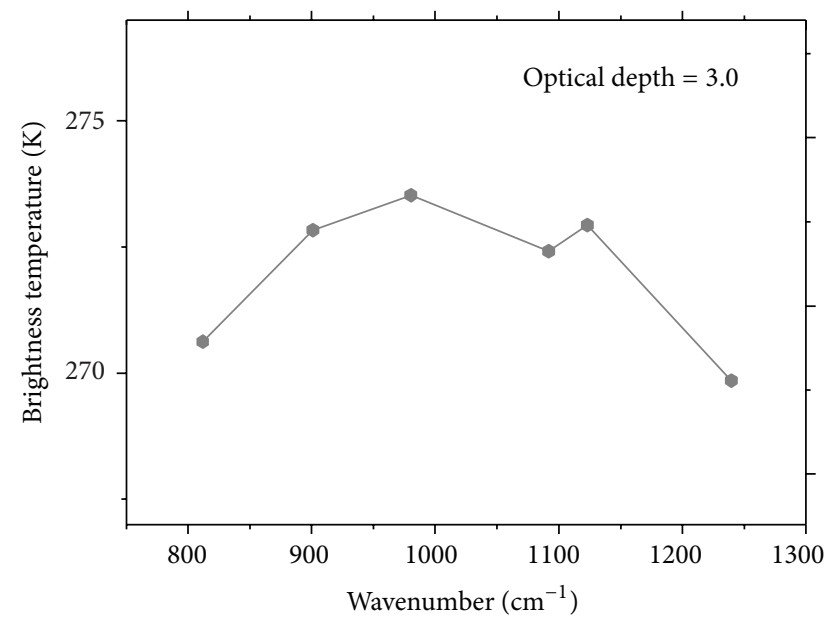

(b)

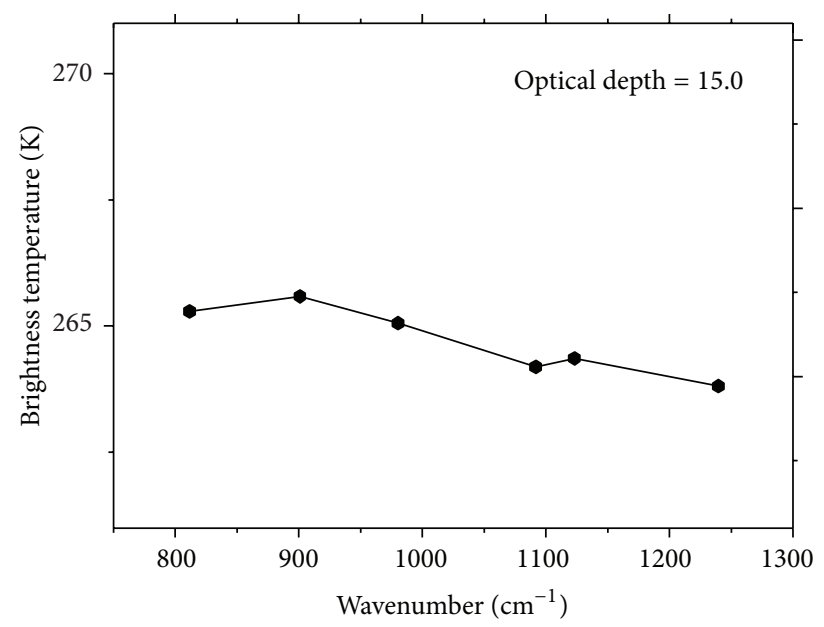

(d)

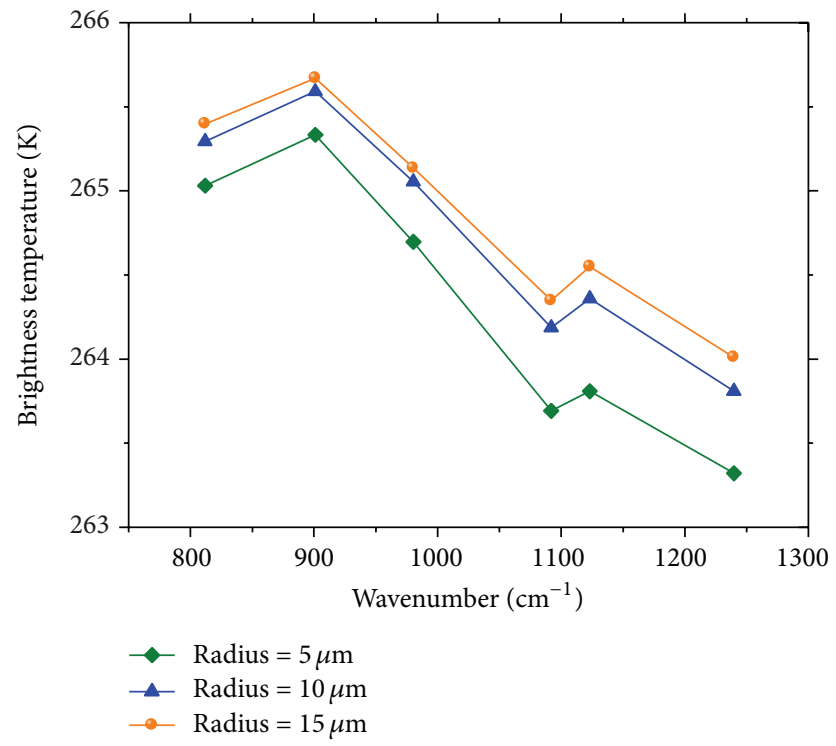

(f)

Figure 4: The effects of (a-d) optical depth, (e) layer height, and (f) effective radius on the spectrum of water cloud. 


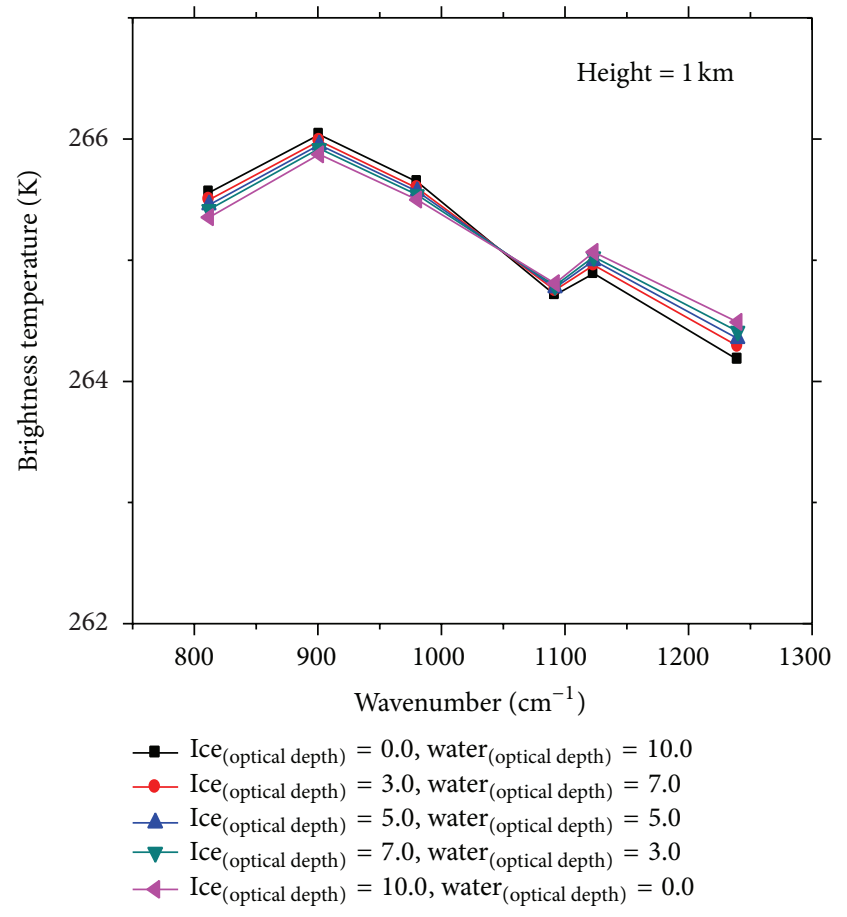

(a)

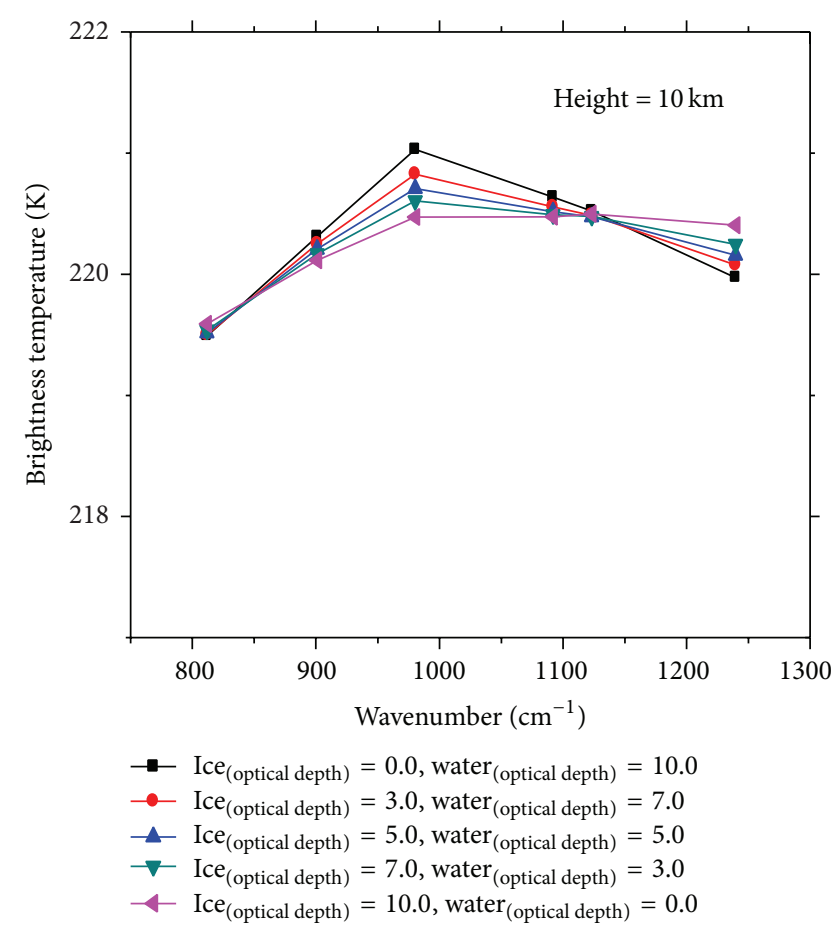

(b)

FIGURE 5: The spectrums of (a) low and (b) high mixed-phase clouds.

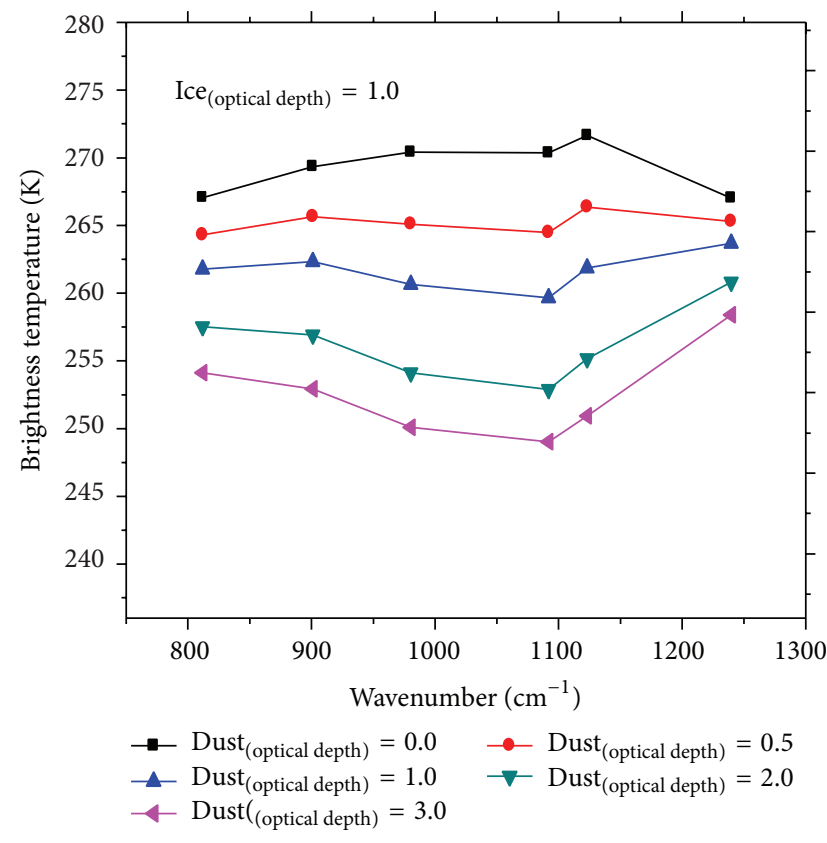

(a)

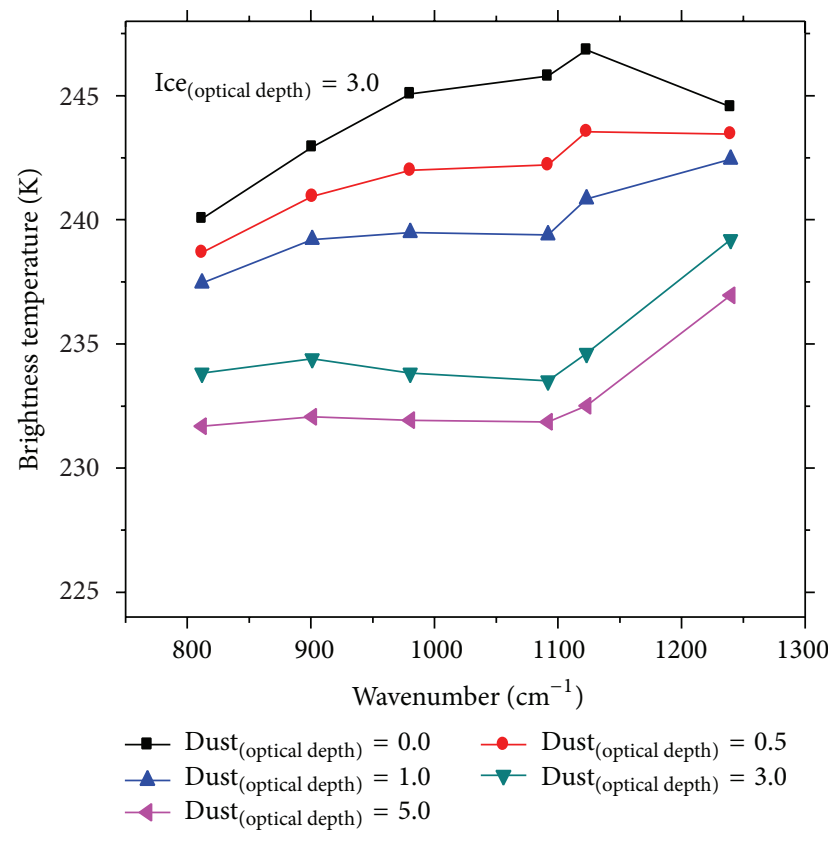

(b)

FIGURE 6: The spectrums of (a) thin and (b) thick ice clouds overlapping underlying dust.

this figure. Moreover, through the comparison of Figures 7(b) and 2, the spectral variation feature that is observed by AIRS is highly corresponding with the forward simulation experiments. This not only implies the correctness of the results discussed in previous context but also indicates that the " $V$ " shape is the true spectral signature of Asia dust in 800$1250 \mathrm{~cm}^{-1}$ region, which gives us more confidence to monitor the Asia dust using this particular characteristic. 


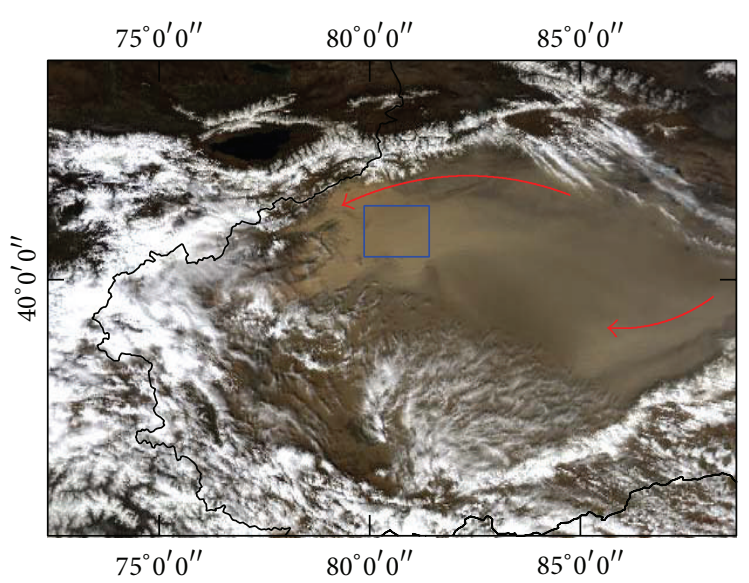

(a)

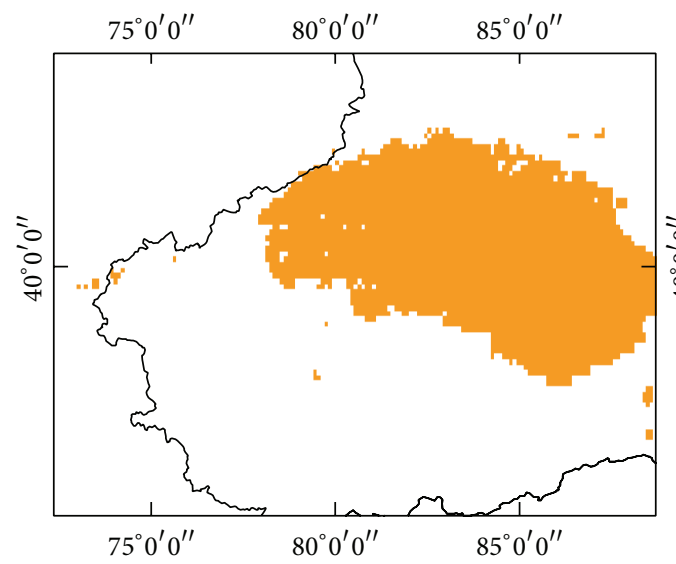

(c)

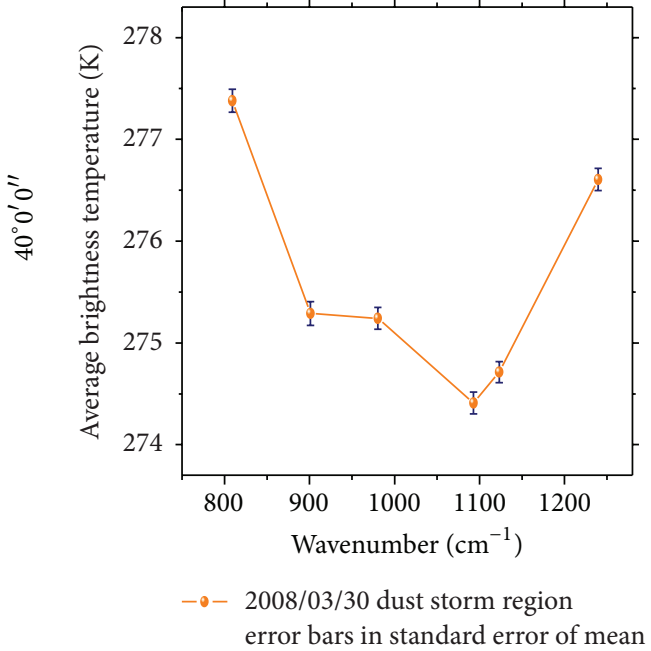

(b)

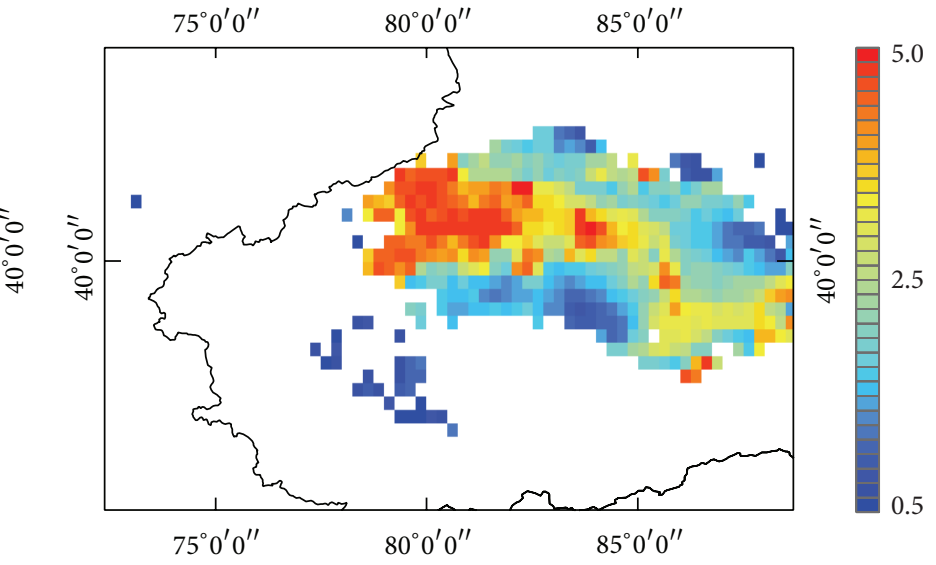

(d)

FIGURE 7: (a) March 30, 2008, dust RGB composite image form MODIS, (b) AIRS observation brightness temperature within dust region, (c) dust identification results, and (d) MODIS deep blue aerosol optical depth results.

TABLE 3: The combinations of ARIS channels and dust identification thresholds.

\begin{tabular}{lcc}
\hline Dust test & Channel combinations & Threshold \\
\hline dustflag1 & $\mathrm{BT}_{811.78 \mathrm{~cm}^{-1}}$ minus $\mathrm{BT}_{901 \mathrm{~cm}^{-1}}$ & Positive \\
dustflag2 & $\mathrm{BT}_{811.78 \mathrm{~cm}^{-1}}$ minus $\mathrm{BT}_{1092.92 \mathrm{~cm}^{-1}}$ & Positive \\
dustflag3 & $\mathrm{BT}_{901 \mathrm{~cm}^{-1} \text { minus } \mathrm{BTBT}_{980.36 \mathrm{~cm}^{-1}}}$ & Positive \\
dustflag4 & $\mathrm{BT}_{901 \mathrm{~cm}^{-1}}$ minus $\mathrm{BT}_{1092.92 \mathrm{~cm}^{-1}}$ & Positive \\
dustflag5 & $\mathrm{BT}_{1092.92 \mathrm{~cm}^{-1}}$ minus $\mathrm{BT}_{1123.13 \mathrm{~cm}^{-1}}$ & Negative \\
dustflag6 & $\mathrm{BT}_{1092.92 \mathrm{~cm}^{-1} \text { minus } \mathrm{BT}_{1239.68 \mathrm{~cm}^{-1}}}$ & Negative \\
dustflag7 & $\mathrm{BT}_{1123.13 \mathrm{~cm}^{-1} \text { minus } \mathrm{BT}_{1239.68 \mathrm{~cm}^{-1}}}$ & Negative \\
\hline
\end{tabular}

Figure $7(\mathrm{c})$ displays the dust identification result based on the proposed method. It is obvious to see that the light brownish dust plumes (red arrow cover region in Figure 7(a)) have been clearly identified by the infrared dust identification algorithm from AIRS observations. Besides, the highly consistent spatial distribution between the dust identification results and MODIS deep blue aerosol optical depth results (Figure 7(d)) also confirms the point. This demonstrates that the selected thermal infrared AIRS channels can effectively identify the dust from other scenes.

4.2. Case: 19 April 2008. On April 19, 2008, a combination of dust and cloud hovered over the most of Taklimakan Desert. The RGB composite image captured by Aqua's MODIS instrument is shown in Figure 8(a). As seen in this image, the strong dust activity originates from eastern Taklimakan Desert, blowing massive loose sand and dust particles to the atmosphere and carrying them to the western areas; red arrows denote the coverage of dust.

Figure 8(b) shows the spectral brightness temperatures within dust regions (the blue box region depicted in Figure 8(a)) observed by the selected infrared channels of AIRS. The thermal infrared signature of this selected dusty area also reveals a similar variation characteristic with the forward simulation results which are displayed in 


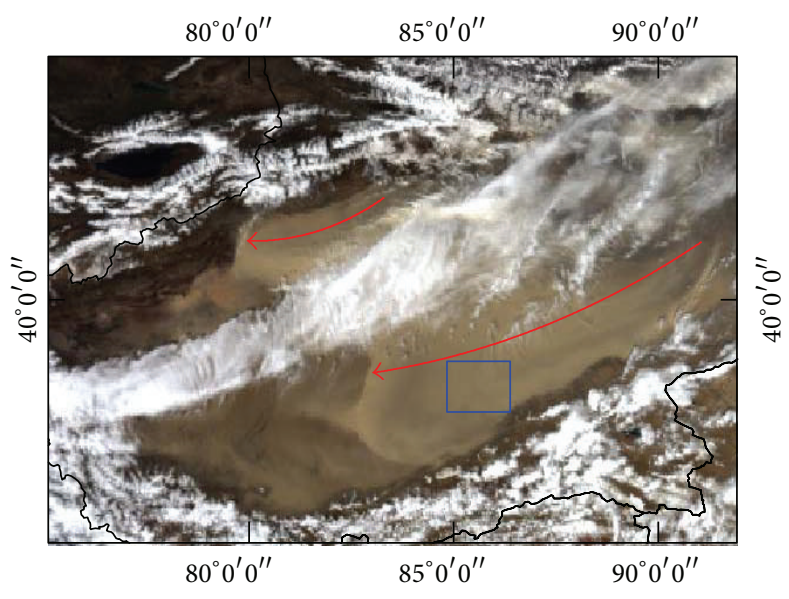

(a)

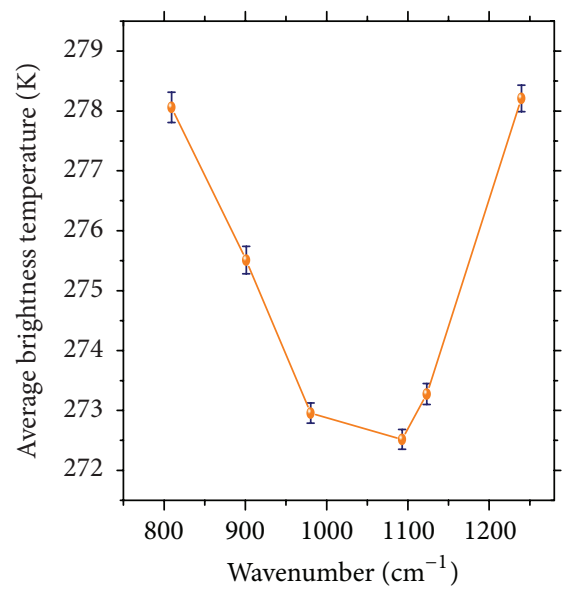

- $-2008 / 04 / 19$ dust storm region error bars in standard error of mean

(b)

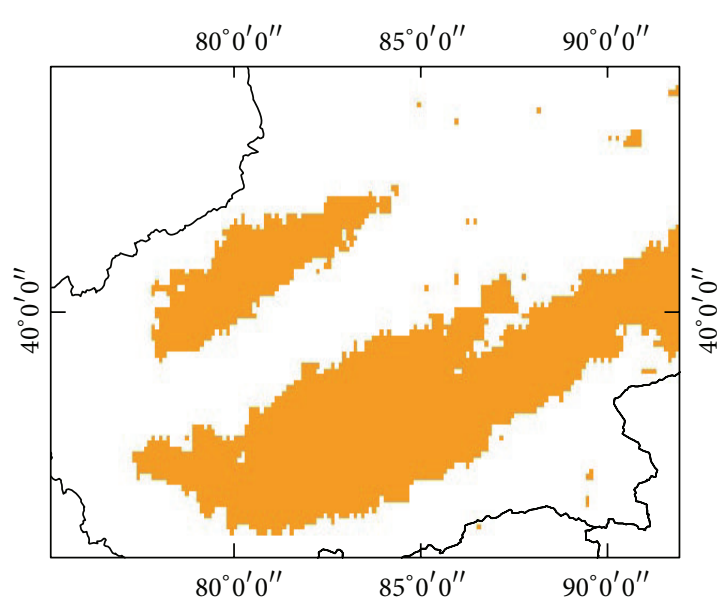

(c)

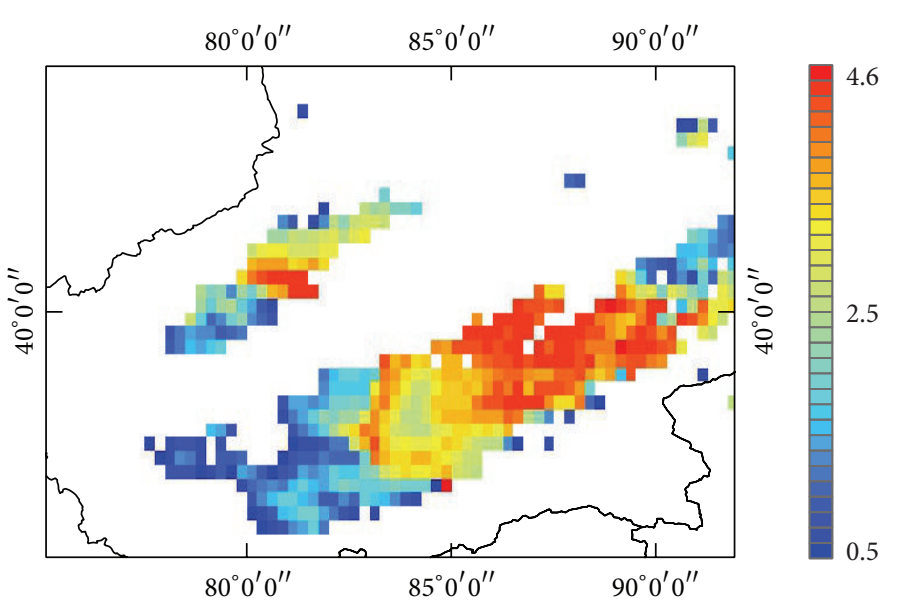

(d)

FIGURE 8: (a) April 19, 2008, dust RGB composite image form MODIS, (b) AIRS observation brightness temperature within dust region, (c) dust identification results, and (d) MODIS deep blue aerosol optical depth results.

Figure 2. This phenomenon proved again that the spectral characteristic of Asia dust discussed in the preceding context is overall correct.

Based on the proposed method, the coverage of this dust event is identified by the selected AIRS channels, which is shown in Figure 8(c). Through the comparison with MODIS composite image, it is clear to see that the dusty areas can be accurately distinguished from cloud and clear sky regions, and the detected results agree well with those shown in the visible observations. In addition, the distribution pattern of retrieved MODIS deep blue optical depth results (Figure $8(\mathrm{~d})$ ) is also highly consistent with the AIRS dust identification results. This indicates that the thermal infrared measurements are indeed able to successfully pick out the dusty regions over bright surface of arid and semiarid regions.
4.3. Case: 25 April 2009. The particular nighttime dust imagery around the Taklimakan desert region on 25 April, 2009 , is selected to illustrate the capability of dust identification at night. Figure 9(a) shows the CALIOP track path (black line), and the pink line segment represents the local footprints in the study areas. The AIRS dust identification results, CALIOP $532 \mathrm{~nm}$ backscatter data (in units of $\mathrm{km}^{-1} \mathrm{sr}^{-1}$ ), and retrieved aerosol subtype results are given in Figures 9(b), $9(\mathrm{c})$, and $9(\mathrm{~d})$, respectively.

Through the comparison of Figures 9 (b) and 9(d), it is intuitive to see that the nighttime AIRS dust identification results along the track agree well with the aerosol type results retrieved from CALIOP, and both of the results indicate that dust exists in large areas from the latitude of $52.25^{\circ}$ to $28.30^{\circ}$. Indeed, as evidently shown in the Lidar 


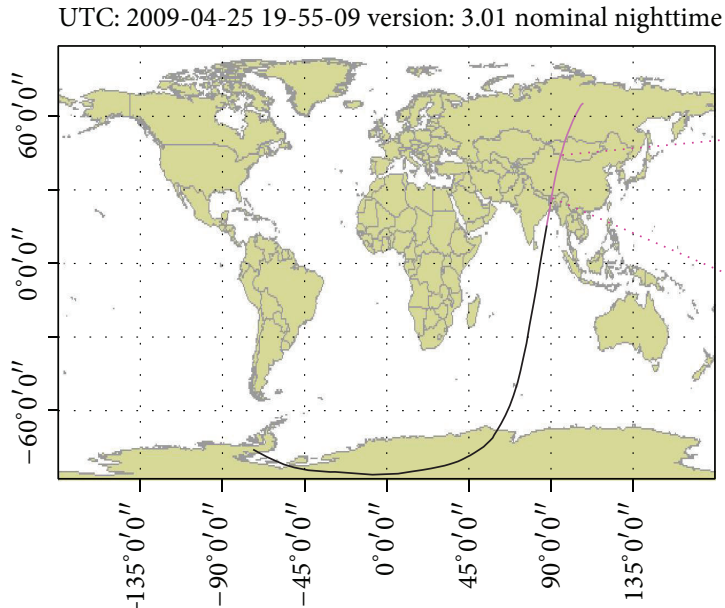

(a)

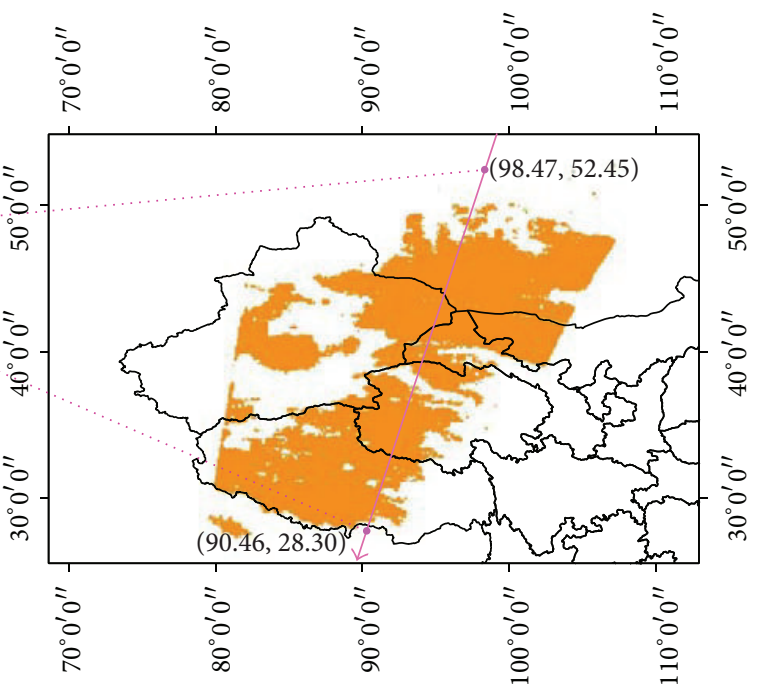

(b)

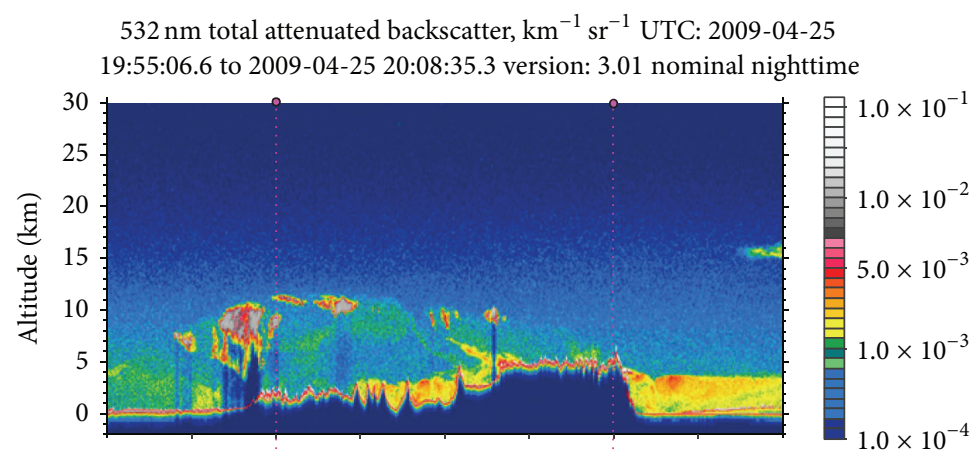

(c)

Aerosol subtype UTC: 2009-04-25 19:55:06.6 to

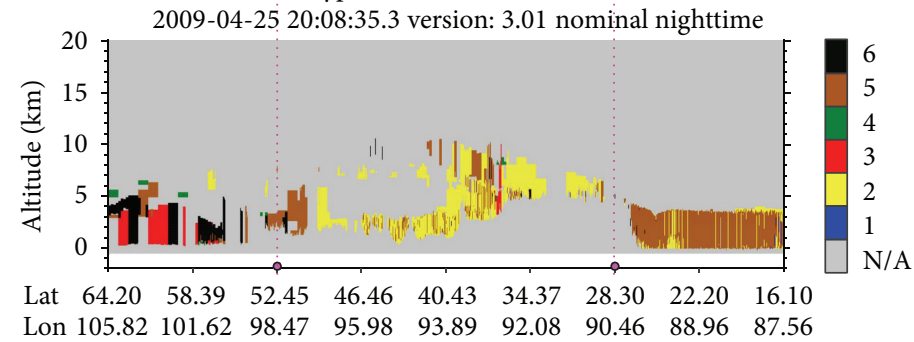
(N/A) Not applicable
(1) Clean marine
(2) Dust
(3) Polluted continental

(4) Clean continental

(5) Polluted dust

(6) Smoke

(d)

FIGURE 9: (a) April 25, 2009, CALIPSO track path, (b) AIRS dust identification results along the CALIPSO track, (c) the vertical backscatter data observed by the CALIOP $532 \mathrm{~nm}$ channel, and (d) the level 2 aerosol subtype results retrieved from CALIOP.

backscatter data (Figure 9(c)), thin dusts (yellow signals) with a top height between $1 \mathrm{~km}$ and $10 \mathrm{~km}$ are present between $52.45^{\circ}$ and $46.46^{\circ}$ latitude, and the ice clouds (pale signals) with geometric depth ranging from $500 \mathrm{~m}$ to $1 \mathrm{~km}$ are also existing in the same region. In addition, the thick dust layer (red signals) located between $1 \mathrm{~km}$ and $2 \mathrm{~km}$ from the latitude of $46.46^{\circ}$ to $34.37^{\circ}$ is observed, and an extra tenuous dust layer (yellow signals) distributed at a high altitude on top of the thick one was also captured by the sensor of CALIOP. In the latitude region of $34.37^{\circ}$ to $28.30^{\circ}$, however, relatively weak backscatter signals were received by the $532 \mathrm{~nm}$ channel, which indicates that little dusts exist in the area. 


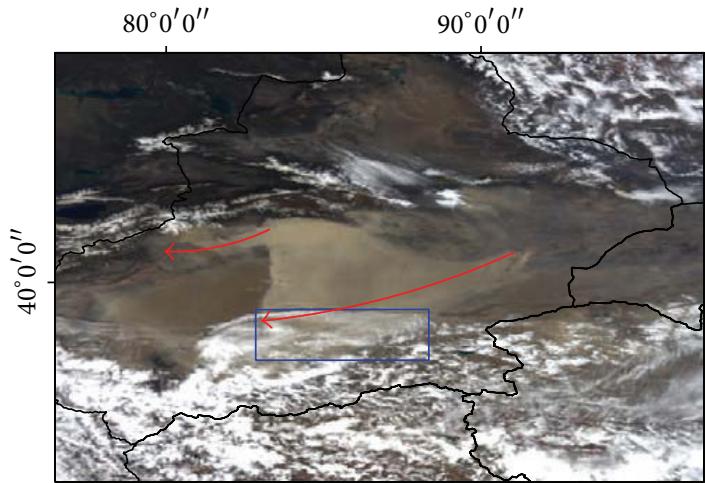

$80^{\circ} 0^{\prime} 0^{\prime \prime}$ $90^{\circ} 0^{\prime} 0^{\prime \prime}$

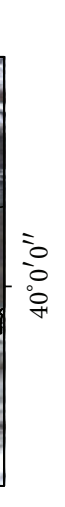

(a)

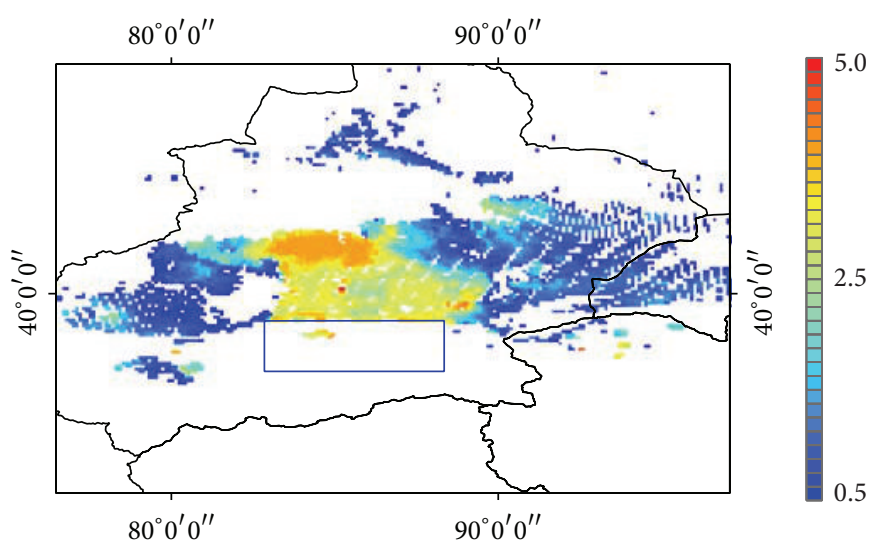

(b)

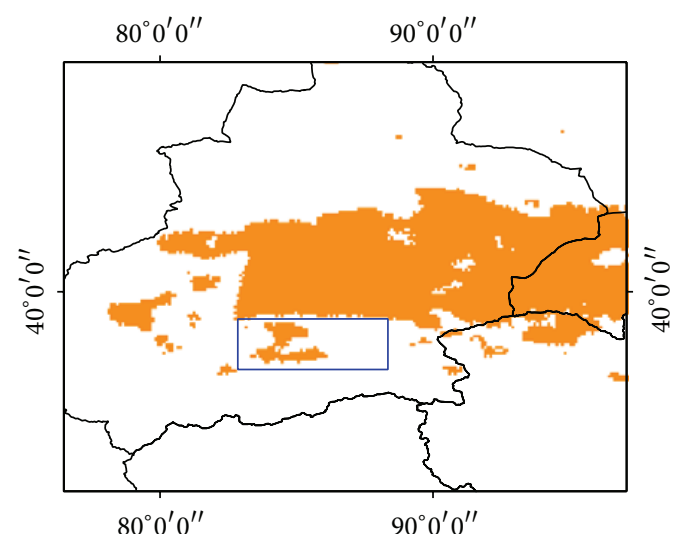

(c)

FIGURE 10: (a) April 23, 2012, dust RGB composite image form MODIS, (b) dust identification results, and (c) MODIS deep blue aerosol optical depth results.

The accurate identification results demonstrate that dust which occurred during nighttime can also be effectively detected through the thermal infrared channels of AIRS.

4.4. Case: 23 April 2012. On 23 April, 2007, dust plumes blew out of the Taklimakan desert toward the west. They are captured by the MODIS image shown in Figure 10(a). In the blue rectangle region, it is clear to see that the clouds and dusts coexisted in the same scene. Figures 10(b) and 10(c) show the spatial distribution of dust identification results from AIRS and deep blue aerosol optical depth results from MODIS.

From Figures 10(b) and 10(c), it is interesting to see that both the infrared and visible measurements can easily detect the outbreaks of dust in the areas of cloud and dust layers which are not cooccurring in the same atmospheric column. However, in the blue rectangle region where dust is overlapped by cloud, only little dusty areas can be identified through the infrared or visible observations, even though some thin ice cloud overlapping areas can be successfully detected by the proposed thermal infrared method. This is because cloud can absolutely cover the visible and infrared spectral signature of underling dust when its optical depth is very high, as discussed in Section 3.3. Thus, dust events might be underestimated under the particular condition, and more remote sensing techniques are required in addition to the visible and infrared to solve this problem, such as the infrared and microwave combined method developed by Huang et al. [28] and the active Lidar and infrared combined method developed by Chen et al. [30].

4.5. Case: 2009 2012. In order to make a further validation on the accuracy of proposed dust identification algorithm, several other dust events that occurred during the period of 2009 and 2012 are performed in the following content. Figure 11 shows the three dust events over different regions of northern China on 15 March, 2009, 11 May, 2011, and 24 April, 2012, respectively. From left to right, the images are MODIS RGB composite image, AIRS dust identification results, and MODIS deep blue aerosol optical depth results.

It is interesting to note that all the light brownish dusty regions (red arrow cover regions) in the MODIS RGB composite images can be well detected by the proposed infrared AIRS dust identification method, and all the detection results are generally consistent with the MODIS deep blue visible optical depth in spatial distribution. As a whole, all the above analyzed dust cases demonstrate that the proposed 


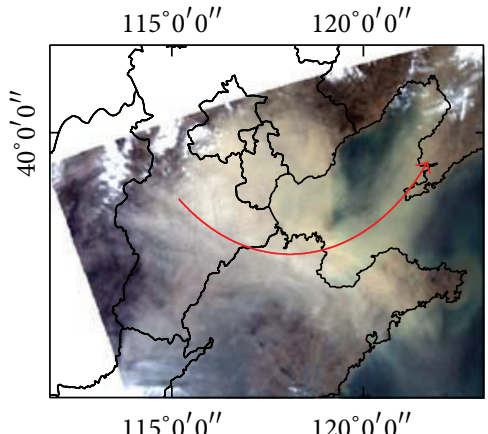

$115^{\circ} 0^{\prime} 0^{\prime \prime} \quad 120^{\circ} 0^{\prime} 0^{\prime \prime}$

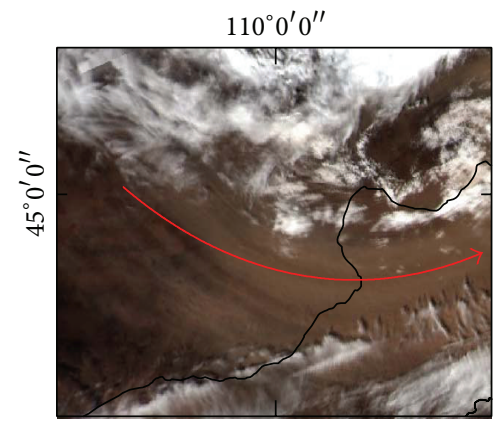

$110^{\circ} 0^{\prime} 0^{\prime \prime}$

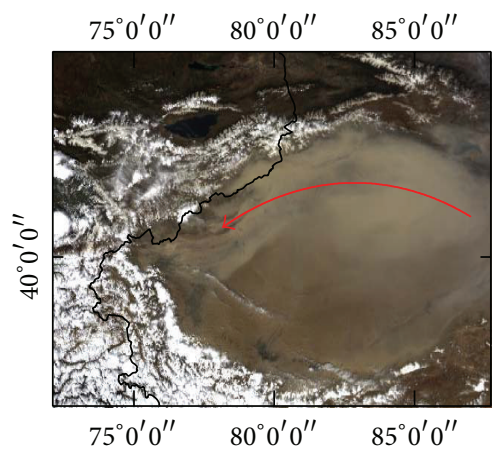

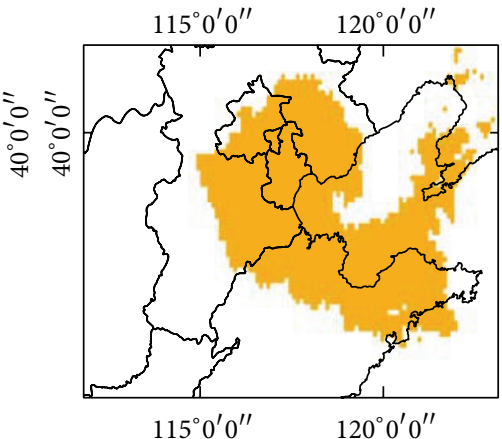

(a)

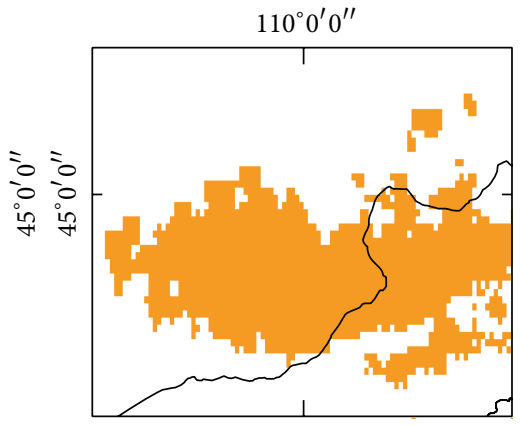

$110^{\circ} 0^{\prime} 0^{\prime \prime}$

(b)
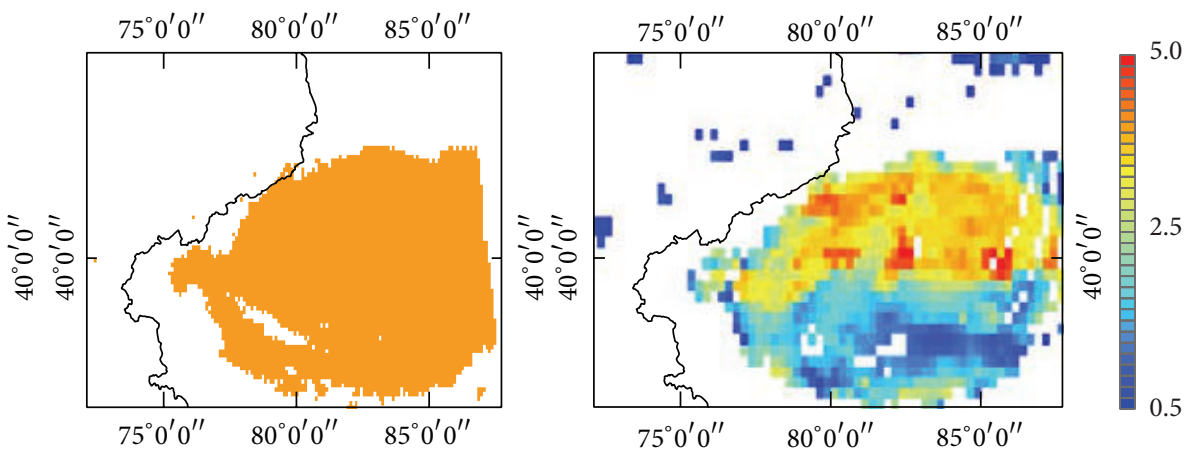
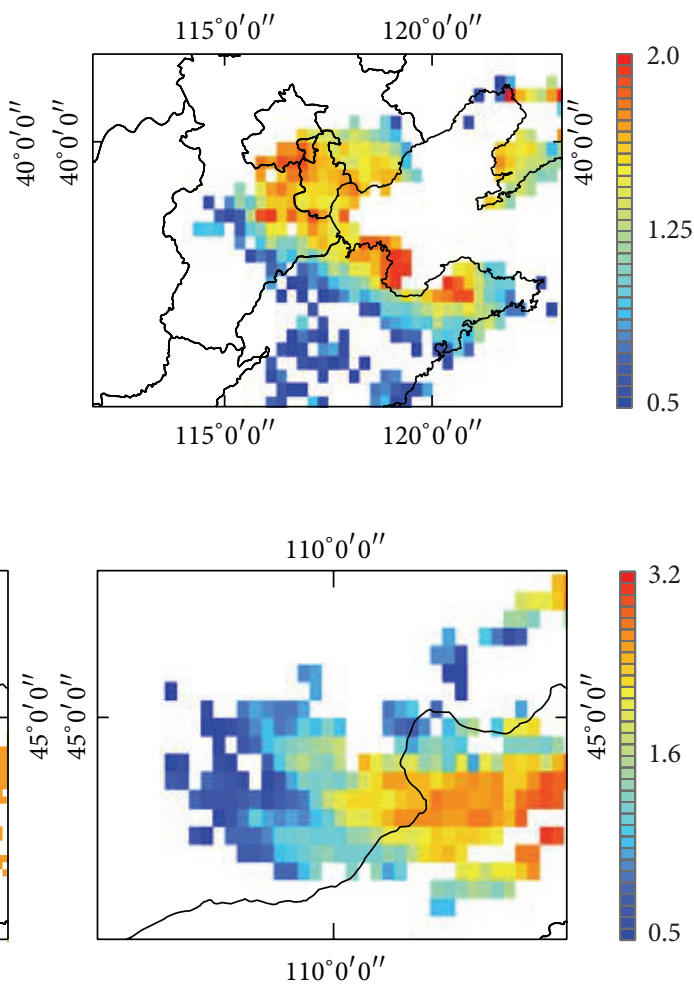

$110^{\circ} 0^{\prime} 0^{\prime \prime}$

(c)

Figure 11: Asia dust events occurred in northern China from 2009 to 2012. (a) 15 March, 2009, (b) 11 May, 2011 , and (c) 24 April, 2012.

identification algorithm in this study is indeed useful and reliable for monitoring the outbreaks and dispersion of Asian dust over arid and semiarid regions.

\section{Conclusion}

The developed thermal infrared dust identification algorithm has been successfully applied to Asia dust in this paper. This method relies on the distinct "V" spectral signature of dust in the $800-1250 \mathrm{~cm}^{-1}$ region, which is resulted from a negative spectral slope in $800-1000 \mathrm{~cm}^{-1}$ subregion and a positive spectral slope in $1060-1250 \mathrm{~cm}^{-1}$ subregion. Through the comparison of dust identification results from AIRS with MODIS visible observations, it suggests that 
and dust coexisting in the same atmospheric column and as the cloud can make a great impact on the spectral signature of underlying dust, therefore, more sensors, channel combinations, and identification criteria are needed to accurately detect dust under this particular scene.

\section{Conflict of Interests}

The authors declare that there is no conflict of interests regarding the publication of this paper.

\section{Acknowledgments}

This study was funded by the Major State Basic Research Development Program of China (no. 2010CB950800) and Natural Science Foundation (no. 41371015). Additionally, the authors thank the GES-DISC and ICARE for providing AIRS and MODIS remote sensing data. At last, they thank the reviewer a lot for all the work done to this paper and are highly appreciating his generous help.

\section{References}

[1] P. Zhang, N.-M. Lu, X.-Q. Hu, and C.-H. Dong, "Identification and physical retrieval of dust storm using three MODIS thermal IR channels," Global and Planetary Change, vol. 52, no. 1-4, pp. 197-206, 2006.

[2] L. Natsagdorj, D. Jugder, and Y. S. Chung, "Analysis of dust storms observed in Mongolia during 1937-1999," Atmospheric Environment, vol. 37, no. 9-10, pp. 1401-1411, 2003.

[3] X. Wang, J. Huang, M. Ji, and K. Higuchi, "Variability of East Asia dust events and their long-term trend," Atmospheric Environment, vol. 42, no. 13, pp. 3156-3165, 2008.

[4] J. Xuan and I. N. Sokolik, "Characterization of sources and emission rates of mineral dust in Northern China," Atmospheric Environment, vol. 36, no. 31, pp. 4863-4876, 2002.

[5] X. Y. Zhang, S. L. Gong, Z. X. Shen et al., "Characterization of soil dust aerosol in China and its transport and distribution during 2001 ACE-Asia: 1. Network observations," Journal of Geophysical Research D: Atmospheres, vol. 108, no. 9, pp. -1-13, 2006.

[6] Y. Shao and C. H. Dong, "A review on East Asian dust storm climate, modelling and monitoring," Global and Planetary Change, vol. 52, no. 1-4, pp. 1-22, 2006.

[7] J. Zhou, G. Yu, C. Jin et al., "Lidar observations of Asian dust over Hefei, China, in spring 2000," Journal of Geophysical Research D: atmospheres, vol. 107, no. 15, pp. -1-8, 2002.

[8] T. Murayama, N. Sugimoto, I. Uno et al., "Ground-based network observation of Asian dust events of April 1998 in East Asia," Journal of Geophysical Research, vol. 106, no. D16, pp. 18345-18360, 2001.

[9] T. Murayama, D. Müller, K. Wada, A. Shimizu, M. Sekiguchi, and T. Tsukamoto, "Characterization of Asian dust and Siberian smoke with multi-wavelength Raman lidar over Tokyo, Japan in spring 2003," Geophysical Research Letters, vol. 31, no. 23, pp. 1-5, 2004.

[10] A. Shimizu, N. Sugimoto, I. Matsui et al., "Continuous observations of Asian dust and other aerosols by polarization lidars in China and Japan during ACE-Asia," Journal of Geophysical Research: Atmospheres, vol. 109, no. D19, pp. D19-S17, 2004.
[11] Y. Gu, W. I. Rose, and G. J. S. Bluth, "Retrieval of mass and sizes of particles in sandstorms using two MODIS IR bands: a case study of April 7, 2001 sandstorm in China," Geophysical Research Letters, vol. 30, no. 15, p. 1805, 2003.

[12] J. Huang, B. Lin, P. Minnis et al., "Satellite-based assessment of possible dust aerosols semi-direct effect on cloud water path over East Asia," Geophysical Research Letters, vol. 33, no. 19, Article ID L19802, 2006.

[13] J. Huang, Y. Wang, T. Wang, and Y. Yi, "Dusty cloud radiative forcing derived from satellite data for middle latitude regions of East Asia," Progress in Natural Science, vol. 16, no. 10, pp. 10841089, 2006

[14] J. Huang, P. Minnis, B. Lin et al., "Possible influences of Asian dust aerosols on cloud properties and radiative forcing observed from MODIS and CERES," Geophysical Research Letters, vol. 33, no. 6, Article ID L06824, 2006.

[15] A. Zhu, V. Ramanathan, F. Li, and D. Kim, "Dust plumes over the Pacific, Indian, and Atlantic oceans: climatology and radiative impact," Journal of Geophysical Research D, vol. 112, no. 16, Article ID D16208, 2007.

[16] T. D. Jickells, Z. S. An, K. K. Andersen et al. et al., "Global iron connections between desert dust, ocean biogeochemistry, and climate," Science, vol. 308, no. 5718, pp. 67-71, 2005.

[17] E.-H. Lee and B.-J. Sohn, "Recent increasing trend in dust frequency over Mongolia and Inner Mongolia regions and its association with climate and surface condition change," Atmospheric Environment, vol. 45, no. 27, pp. 4611-4616, 2011.

[18] J. J. Qu, X. Hao, M. Kafatos, and L. Wang, "Asian dust storm monitoring combining terra and aqua MODIS SRB measurements," IEEE Geoscience and Remote Sensing Letters, vol. 3, no. 4, pp. 484-486, 2006.

[19] O. Torres, P. K. Bhartia, J. R. Herman, Z. Ahmad, and J. Gleason, "Derivation of aerosol properties from satellite measurements of backscattered ultraviolet radiation: theoretical basis," Journal of Geophysical Research, vol. 103, no. 14, pp. 17099-17110, 1998.

[20] N. C. Hsu, S.-C. Tsay, M. D. King, and J. R. Herman, "Aerosol properties over bright-reflecting source regions," IEEE Transactions on Geoscience and Remote Sensing, vol. 42, no. 3, pp. 557$569,2004$.

[21] M. Legrand, A. Plana-Fattori, and C. N'Doumé, "Satellite detection of dust using the IR imagery of Meteosat 1. Infrared difference dust index," Journal of Geophysical Research D: Atmospheres, vol. 106, no. 16, pp. 18251-18274, 2001.

[22] J. K. Roskovensky and K. N. Liou, "Differentiating airborne dust from cirrus clouds using MODIS data," Geophysical Research Letters, vol. 32, no. 12, Article ID L12809, 2005.

[23] H. E. Brindley and J. E. Russell, "Improving GERB scene identification using SEVIRI: infrared dust detection strategy," Remote Sensing of Environment, vol. 104, no. 4, pp. 426-446, 2006.

[24] J. Li, P. Zhang, T. J. Schmit, J. Schmetz, and W. P. Menzel, "Quantitative monitoring of a Saharan dust event with SEVIRI on Meteosat-8," International Journal of Remote Sensing, vol. 28, no. 10, pp. 2181-2186, 2007.

[25] X. Q. Hu, N. M. Lu, T. Niu, and P. Zhang, "Operational retrieval of Asian sand and dust storm from FY-2C geostationary meteorological satellite and its application to real time forecast in Asia," Atmospheric Chemistry and Physics, vol. 8, no. 6, pp. 1649-1659, 2008.

[26] C. Pierangelo, A. Chédin, S. Heilliette, N. Jacquinet-Husson, and R. Armante, "Dust altitude and infrared optical depth from 
AIRS," Atmospheric Chemistry and Physics, vol. 4, no. 7, pp. 18131822, 2004.

[27] L. Klüser, D. Martynenko, and T. Holzer-Popp, “Thermal infrared remote sensing of mineral dust over land and ocean: a spectral SVD based retrieval approach for IASI," Atmospheric Measurement Techniques, vol. 4, no. 5, pp. 757-773, 2011.

[28] J. Huang, J. Ge, and F. Weng, "Detection of Asia dust storms using multisensor satellite measurements," Remote Sensing of Environment, vol. 110, no. 2, pp. 186-191, 2007.

[29] J. Ge, J. Huang, F. Weng, and W. Sun, "Effects of dust storms on microwave radiation based on satellite observation and model simulation over the Taklamakan desert," Atmospheric Chemistry and Physics, vol. 8, no. 16, pp. 4903-4909, 2008.

[30] B. Chen, J. Huang, P. Minnis et al., "Detection of dust aerosol by combining CALIPSO active lidar and passive IIR measurements," Atmospheric Chemistry and Physics, vol. 10, no. 9, pp. 4241-4251, 2010.

[31] I. N. Sokolik, "The spectral radiative signature of wind-blown mineral dust: implications for remote sensing in the thermal IR region," Geophysical Research Letters, vol. 29, no. 24, pp. 7-1-7-4, 2002.

[32] G. Hong, P. Yang, H.-L. Huang, S. A. Ackerman, and I. N. Sokolik, "Simulation of high-spectral-resolution infrared signature of overlapping cirrus clouds and mineral dust," Geophysical Research Letters, vol. 33, no. 4, Article ID L04805, 2006.

[33] C. Pierangelo, M. Mishchenko, Y. Balkanski, and A. Chédin, "Retrieving the effective radius of Saharan dust coarse mode from AIRS," Geophysical Research Letters, vol. 32, no. 20, Article ID L20813, pp. 1-4, 2005.

[34] S. Peyridieu, A. Chédin, D. Tanré et al., "Saharan dust infrared optical depth and altitude retrieved from AIRS: a focus over North Atlantic-comparison to MODIS and CALIPSO," Atmospheric Chemistry and Physics, vol. 10, no. 4, pp. 1953-1967, 2010.

[35] S. G. DeSouza-Machado, L. L. Strow, S. E. Hannon, and H. E. Motteler, "Infrared dust spectral signatures from AIRS," Geophysical Research Letters, vol. 33, no. 3, Article ID L03801, 2006.

[36] S. G. Desouza-Machado, L. L. Strow, B. Imbiriba et al., "Infrared retrievals of dust using AIRS: comparisons of optical depths and heights derived for a North African dust storm to other collocated EOS A-Train and surface observations," Journal of Geophysical Research, vol. 115, no. 15, Article ID D15201, 2010.

[37] Z. Yao, J. Li, H.-J. Han, A. Huang, B. J. Sohn, and P. Zhang, "Asian dust height and infrared optical depth retrievals over land from hyperspectral longwave infrared radiances," Journal of Geophysical Research D: Atmospheres, vol. 117, Article ID D19202, 2012.

[38] M. T. Chahine, T. S. Pagano, H. H. Aumann et al., "AIRS: improving weather forecasting and providing new data on greenhouse gases," Bulletin of the American Meteorological Society, vol. 87, no. 7, pp. 911-926, 2006.

[39] J. Susskind, C. D. Barnet, and J. M. Blaisdell, "Retrieval of atmospheric and surface parameters from AIRS/AMSU/HSB data in the presence of clouds," IEEE Transactions on Geoscience and Remote Sensing, vol. 41, no. 2, pp. 390-409, 2003.

[40] J. Li, H.-L. Huang, C.-Y. Liu et al., "Retrieval of cloud microphysical properties from MODIS and AIRS," Journal of Applied Meteorology, vol. 44, no. 10, pp. 1526-1543, 2005.

[41] E. Weisz, J. Li, J. Li et al., "Cloudy sounding and cloud-top height retrieval from AIRS alone single field-of-view radiance measurements," Geophysical Research Letters, vol. 34, no. 12, Article ID L12802, 2007.
[42] W. L. Barnes, T. S. Pagano, and V. V. Salomonson, "Prelaunch characteristics of the moderate resolution imaging spectroradiometer (MODIS) on EOS-AMI," IEEE Transactions on Geoscience and Remote Sensing, vol. 36, no. 4, pp. 1088-1100, 1998.

[43] L. A. Remer, Y. J. Kaufman, D. Tanré et al., "The MODIS aerosol algorithm, products, and validation," Journal of the Atmospheric Sciences, vol. 62, no. 4, pp. 947-973, 2005.

[44] P. Yang, Q. Feng, G. Hong et al., "Modeling of the scattering and radiative properties of nonspherical dust-like aerosols," Journal of Aerosol Science, vol. 38, no. 10, pp. 995-1014, 2007.

[45] H.-J. Han, B.-J. Sohn, H.-L. Huang, E. Weisz, R. Saunders, and T. Takamura, "An improved radiance simulation for hyperspectral infrared remote sensing of Asian dust," Journal of Geophysical Research D, vol. 117, no. 9, Article ID D09211, 2012.

[46] F. E. Volz, "Infrared refractive index of atmospheric aerosolsubstances," Applied Optics, vol. 11, no. 4, pp. 755-759, 1972.

[47] M. Hess, P. Koepke, and I. Schult, "Optical properties of aerosols and clouds: the software package OPAC," Bulletin of the American Meteorological Society, vol. 79, no. 5, pp. 831-844, 1998.

[48] B. Mayer and A. Kylling, "Technical note: the libRadtran software package for radiative transfer calculations-description and examples of use," Atmospheric Chemistry and Physics, vol. 5, no. 7, pp. 1855-1877, 2005.

[49] B. A. Baum, A. J. Heymsfield, P. Yang, and S. T. Bedka, "Bulk scattering properties for the remote sensing of ice clouds. Part I: microphysical data and models," Journal of Applied Meteorology, vol. 44, no. 12, pp. 1885-1895, 2005.

[50] B. A. Baum, P. Yang, A. J. Heymsfield et al., "Bulk scattering properties for the remote sensing of ice clouds. part II: narrowband models," Journal of Applied Meteorology, vol. 44, no. 12, pp. 1896-1911, 2005.

[51] J. P. Huang, P. Minnis, B. Chen et al., "Long-range transport and vertical structure of Asian dust from CALIPSO and surface measurements during PACDEX," Journal of Geophysical Research D: Atmospheres, vol. 113, no. 23, Article ID D23212, 2008.

[52] K. N. Liou, "Parameterization of the radiative properties of cirrus clouds," Journal of the Atmospheric Sciences, vol. 50, no. 13, pp. 2008-2025, 1993.

[53] S. S. C. Ou, K. N. Liou, X. J. Wang et al., "Retrievals of mixedphase cloud properties during the National Polar-Orbiting Operational Environmental Satellite System," Applied Optics, vol. 48, no. 8, pp. 1452-1462, 2009. 

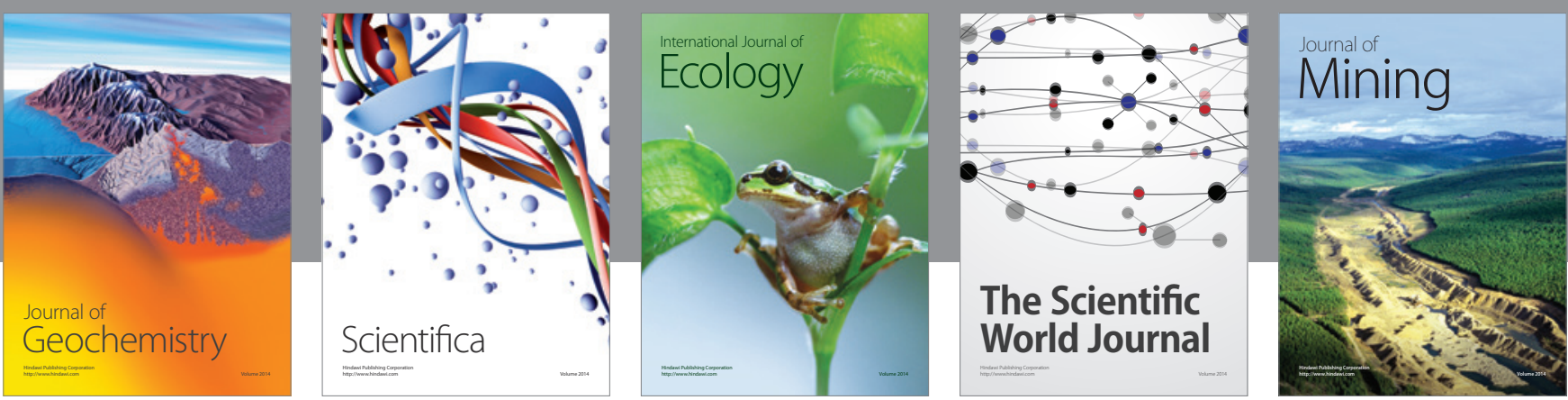

The Scientific World Journal
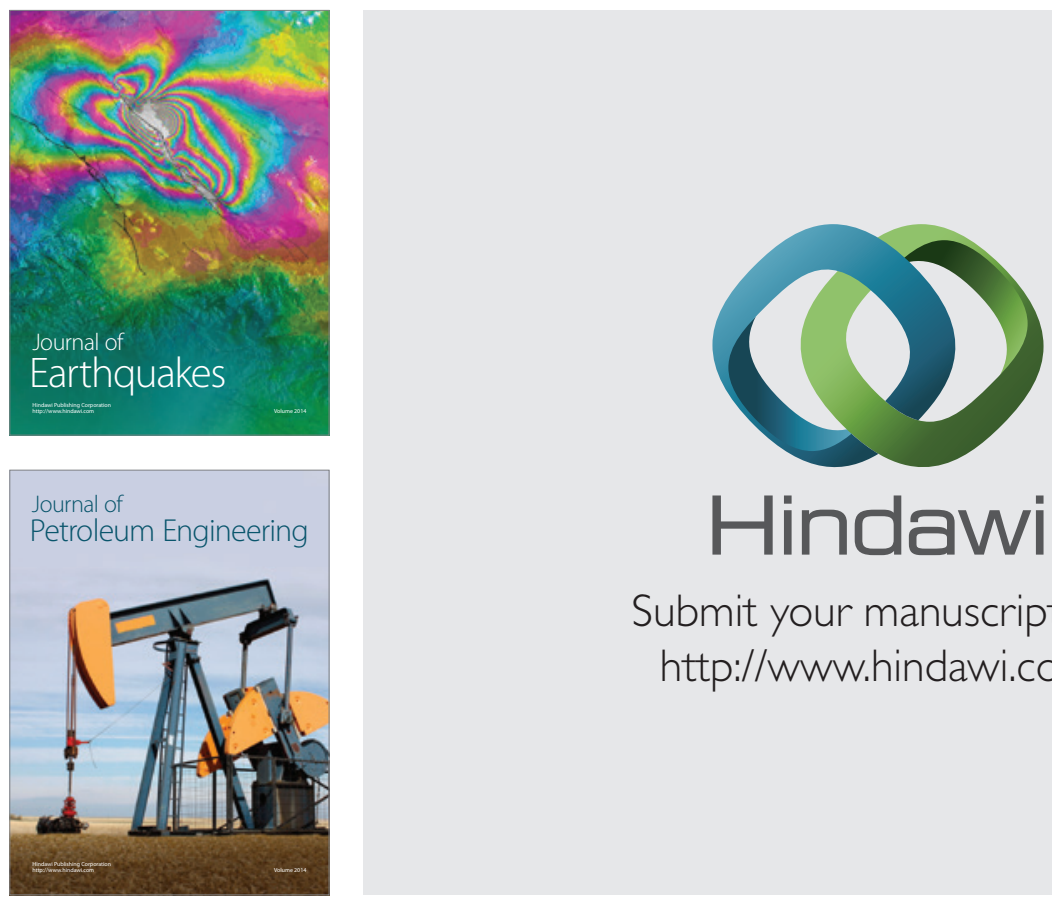

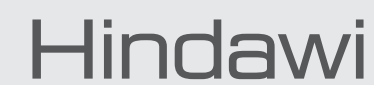

Submit your manuscripts at

http://www.hindawi.com
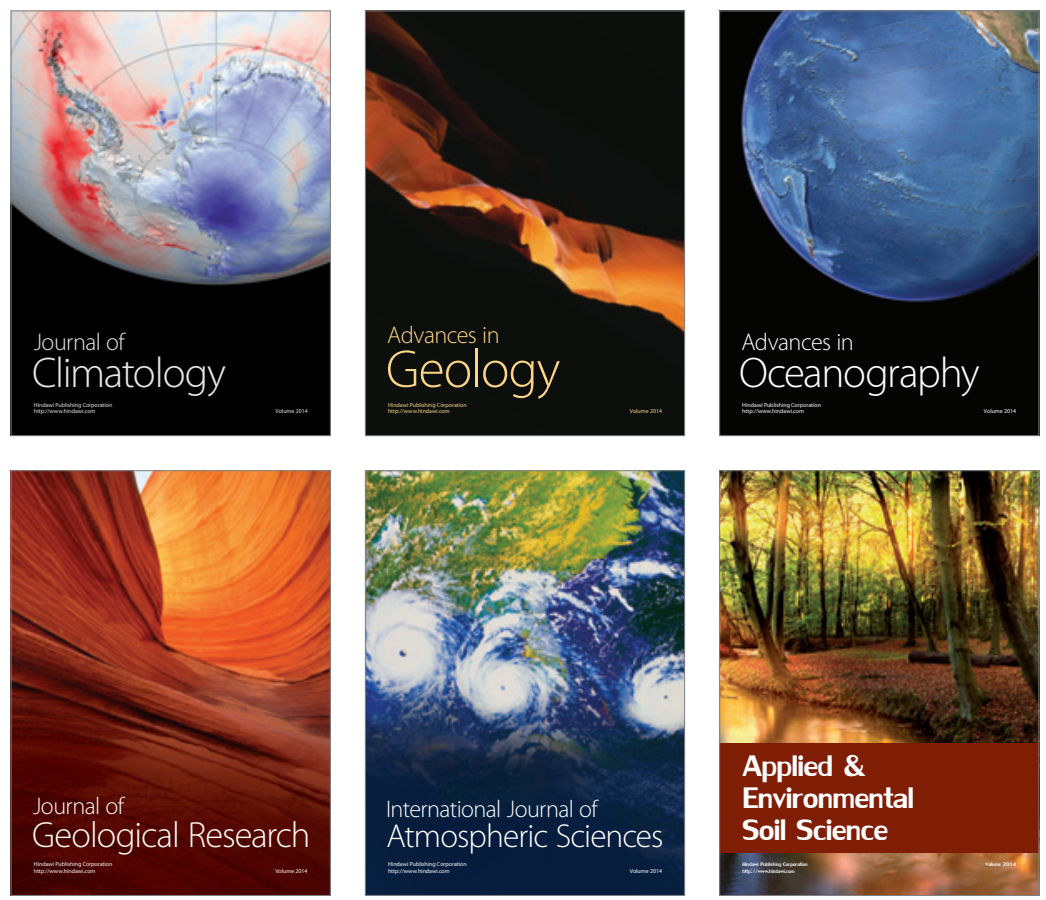
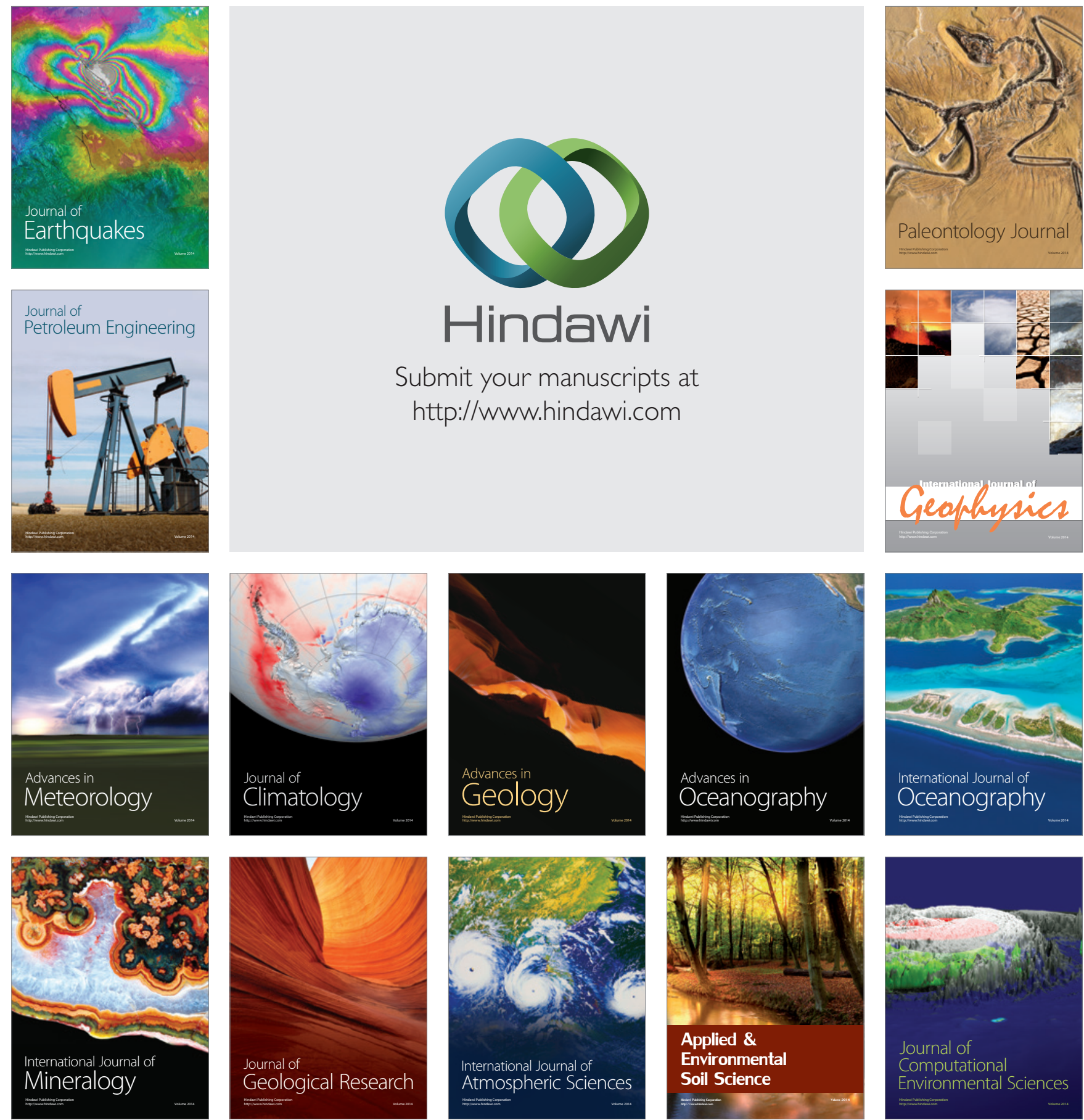